\title{
Preferentna imena konstitucijskih jedinica koja se upotrebljavaju u imenima polimera na osnovi strukture (I. dio) ${ }^{* * *}$
}

\section{Preporuke IUPAC 2016. \\ Preporuke HDKI i HKD 2018.}

Pripravila radna skupina u sastavu:

Werner Mormann, ${ }^{* *}$ Karl-Heinz Hellwich, ${ }^{* *}$ Jiazhong Chen i Edward S. Wilks

Prevela:

Vida Jarm*

Rudolfa Bićanića, 10000 Zagreb

uz savjete i komentare

Marice Ivanković, Jelene Macan i Zorice Veksli

\begin{abstract}
Sažetak
Načinjen je popis konstitucijskih jedinica, KJ, tablica 1, koje se u skladu s pravilima IUPAC-ovog imenovanja upotrebljavaju za tvorbu imena polimera. Popis sadržava KJ-e komercijalnih i dobro poznatih polimera kao i KJ-e pomoću kojih su imenovani polimeri u IUPAC-ovim dokumentima. Za svaku je konstitucijsku jedinicu dano preferentno ime. Popis sadržava i druga prihvatljiva imena te imena koja se zbog zastarjelosti ili netočnosti ne bi trebala upotrebljavati iako su u prošlosti ili u drugim okolnostima upotrebljavana kao točna. U tablici 2 navedena su imena najčešćih polimera i to na osnovi strukture, na osnovi podrijetla i zadržana uvriježena imena polimera kao i imena koja su zbog zastarjelosti i netočnosti neprihvatljiva. Obje tablice zamjenjuju slične tablice i imena, sadržane u prethodnim dokumentima. Pravila navedena u tim dokumentima i dalje vrijede, a imena konstitucijskih jedinica treba prilagoditi pravilima ovog dokumenta. Preferentna imena konstitucijskih jedinica navedena u tablici 1 treba upotrebljavati u imenovanju na osnovi strukture pravilnih i nepravilnih polimera.
\end{abstract}

\section{Ključne riječi}

Imena konstitucijskih jedinica, imena najčešćih polimera, imenovanje polimera, IUPAC-ovo imenovanje, preferentno ime konstitucijske jedinice za imenovanje polimera (PIP)

\section{Sadržaj}

PIP-0 UVOD

PIP-1 NAČELA IMENOVANJA POLIMERA

NA OSNOVI STRUKTURE

PIP-2 KONSTITUCIJSKE JEDINICE ZA IMENOVANJE POLIMERA

Literatura

Summary

\footnotetext{
* Dr. sc. Vida Jarm, vida.jarm@inet.hr

Recenzenti: Marko Rogošić, Ivan Šmit, Andreja Jakas, Lidija Varga-Defterdarović

** Autori za dopisivanje: Werner Mormann, Department Chemie-Biologie, Universität Siegen, Adolf-Reichwein-Straße 2, 57068 Siegen, Germany, e-mail: mormann@chemie.uni-siegen.de; Karl-Heinz Hellwich, Beilstein-Institut zur Förderung der Chemischen Wissenschaften, Trakehner Str. 7-9, 60487 Frankfurt, Germany, e-pošta: hellwich.iupac@gmx.de. *** Izvornik: Werner Mormann, Karl-Heinz Hellwich, Jiazhong Chen, Edward S. Wilks, Prefered names of constitutional units for use in structure-based names of polymers (IUPAC Recommendations 2016), Pure Appl. Chem. 89 (11) (2017) 1695-1736, doi: https://doi.org/10.1515/ pac-2016-0502.
}

\section{PIP-0 UVOD}

Kemijsko imenovanje polimernih tvari u neprestanom je razvoju. Posljednjih su desetljeća više puta mijenjana i osnovna načela i pojedinosti imenovanja polimera. Evo nekoliko primjera: u prvom IUPAC-ovom dokumentu o imenovanju jednonitnih polimera na osnovi strukture ${ }^{1}$ ime polimera dobivenog kationskom polimerizacijom tetrahidrofurana (oksolan) bilo je poli(oksitetrametilen). $U$ to vrijeme polipropilen je bilo sustavno ime, ime konstitucijske jedinice $-\mathrm{CH}_{2}-\mathrm{CH}_{2}-$ bilo je etilen, a konstitucijske jedinice $-\mathrm{CH}=\mathrm{CH}-\mathrm{CH}_{2}-\mathrm{CH}_{2}-1$-butenilen. Razvoj imenovanja organsko-kemijskih spojeva potaknuo je promjene prvog dokumenta, ${ }^{1}$ koje su tiskane u drugom dokumentu objavljenom 2002. ${ }^{2}$ Umjesto imena konstitucijskih jedinica tipa "polimetileni" (npr. heksametilen) kao i imena alkilena (npr. butilen), uvode se imena alkan-1,x-diil kao i druge promjene u skladu s organsko-kemijskim imenovanjem. ${ }^{3,4}$ Dodatne manje promjene drugog dokumenta ${ }^{2}$ načinjene su i u drugom izdanju IUPAC-ove knjige "Compendium of Polymer Terminology and Nomenclature" ("Ljubičasta knjiga" - "The Purple Book"). ${ }^{5}$ Promjene načinjene i u naj- 
novijim IUPAC-ovim izdanjima knjiga "Nomenclature of Organic Chemistry" ("Plava knjiga" - "The Blue Book") ${ }^{6}$ i "Nomenclature of Inorganic Chemistry" ("Crvena knjiga" -"The Red Book") ${ }^{7}$ također utječu na imenovanje polimera.

Postoje dva glavna načina imenovanja polimera, ${ }^{5}$ imenovanje na osnovi podrijetla i imenovanjeje na osnovi strukture. Kod imenovanja na osnovi podrijetla upotrebljavaju se IUPAC-ova imena monomera od kojih je, stvarno ili prividno, polimer dobiven. Imenovanje na osnovi strukture upotrebljava IUPAC-ova imena konstitucijskih jedinica koje tvore makromolekule. Konstitucijske jedinice navedene $u$ tablici 1 toga dokumenta namijenjene su samo za tvorbu imena polimera na osnovi strukture. Za imenovanje polimera na osnovi podrijetla upotrebljavaju se imena konstitucijskih jedinica i monomernih jedinica sadržanih u IUPAC-ovim preporukama za imenovanje organske kemije, ${ }^{6}$ anorganske kemije ${ }^{7} \mathrm{i}$ u preporukama sadržanim u novome dokumentu za imenovanje na osnovi podrijetla. ${ }^{8}$

Objavljena pravila ${ }^{2,5}$ daju jasne upute o načinu određivanja ponavljane konstitucijske jedinice $(\mathrm{PKJ})$ i redoslijeda podjedinica u pravilnoj makromolekuli. Ta pravila daju jedan preferentan PKJ, tj. jedinstvenu strukturu (slijed konstitucijskih jedinica) koja je temelj imenovanja polimera na osnovi strukture. Međutim mnoge se konstitucijske jedinice (KJ) mogu različito imenovati, što omogućuje i različita imenovanja određenoga polimera. Prihvaćanje različitih mogućnosti imenovanja u različitim razdobljima dovelo je do neujednačenosti.

Glavno pravilo u imenovanju polimera je da imena konstitucijskih jedinica i monomernih jedinica moraju biti u skladu s preporukama imenovanja u organskoj kemiji. Prema tome bi se u imenovanju polimera na osnovi strukture za svaku konstitucijsku jedinicu trebala upotrebljavati imena odgovarajućih skupina organske kemije. Iz toga proizlazi kako ne bi trebalo biti razlike u imenovanju konstitucijskih jedinica (KJ) ili ponavljanih konstitucijskih jedinica (PKJ). Međutim imenovanje polimera ima i neke specifičnosti, koje će u brojnim primjerima rezultirati različitim imenima. Jedna od specifičnosti je osnovno pravilo za imenovanje na osnovi strukture koje kaže da se skupine koje ne tvore glavni lanac makromolekule uvijek imenuju kao supstituenti. To je pravilo važnije od gore spomenutoga glavnoga pravila i prema njemu će imena brojnih PKJ-a biti različita od imena koja ti PKJ-i imaju prema pravilima imenovanja u organskoj kemiji.

Na primjer, ime skupine $-\mathrm{CH}\left(\mathrm{CH}_{3}\right)-\mathrm{CH}_{2}-\mathrm{u}$ organskoj kemiji je propan-1,2-diil. To se ime ne upotrebljava u imenovanju polimera, jer već redoslijed lokanata (-1,2-) ukazuje na drugačiju orijentaciju konstitucijske jedinice. Prema pravilima odabira preferentnog PKJ-a ime bi trebalo biti propan-2,1-diil. Međutim važnije je osnovno pravilo da se skupine koje ne tvore glavni lanac imenuju kao supstituenti (ovdje je to metilna skupina) i prema kojemu skupina $\mathrm{CH}_{2}-\mathrm{CH}_{2}-$ čini glavni lanac. Prema tom pravilu ime skupine je 1-metiletilen ili sustavnije 1-metiletan-1,2-diil. Poput toga primjera i brojna druga preferentna imena trebala bi, prema imenovanju organske kemije, biti neprihvatljiva za imenovanje polimera. No i pored toga za svaki se dio konstitucijske jedinice (strukture) upotrebljava odgovaraju- će ime kojim se koristi i u imenovanju organske kemije. Ta se načela primjenjuju i pri imenovanju anorganskih te hibridnih organsko-anorganskih polimera.

Drugi je primjer skupina $-\mathrm{CH}_{2}-\mathrm{CH}_{2}-$, vrlo važan $\mathrm{KJ} \mathrm{u}$ imenovanju polimera i možda jedan od najčešćih KJ-a u imenovanju polimera. Postoje dva imena te konstitucijske jedinice:

- uvriježeno ime etilen i

- sustavno ime etan-1,2-diil.

Prvo je ime rašireno u općoj uporabi, a drugo se ime prema lit. ${ }^{6}$ preporučuje kao preferentno IUPAC-ovo ime uz objašnjenje da je to sustavnije ime.

U "Ljubičastoj knjizi" ("Purple Book") ime etilen zamijenjeno je imenom etan-1,2-diil što daje nova i dulja imena za velik broj polimera (osobito komercijalnih polimera), a bez nekih prednosti. ${ }^{5}$ Zato je dana preporuka da u imenovanju polimera na osnovi strukture preferentno ime skupine $-\mathrm{CH}_{2}-\mathrm{CH}_{2}-$ ostane etilen. Nepotrebna zamjena tih imena u "Ljubičastoj knjizi" 5 načinjena je temeljem pogrešne pretpostavke da će u "Plavoj knjizi" ("Blue Book") ime etilen biti potpuno odbačeno.

Cilj preporuka u ovome dokumentu je ukloniti neujednačenosti u imenovanju polimera na osnovi strukture, objasniti zašto se i dalje preporučuju različita imena konstitucijskih jedinica te koja su preferentna imena među nekoliko prihvatljivih alternativnih imena. Dokument je ograničen na jednonitne polimere, jer glavnina polimera ima upravo takve strukturne značajke.

Dokument pretežito čine tablice ispod kojih su napomene s objašnjenjima i uputama za primjenu tablica. Kako će se cijeli dokument moći pretraživati, autori se nadaju da će se svatko tko se bavi imenovanjem polimera koristiti tom zbirkom konstitucijskih jedinica za točno imenovanje polimera.

Preferentna imena konstitucijskih jedinica u tablici 1 treba upotrebljavati u imenima na osnovi strukture pravilnih i nepravilnih polimera (npr. ponavljanih konstitucijskih jedinica, podjedinica ponavljanih konstitucijskih jedinica, vezujućih jedinica i u imenima pojedinačnih konstitucijskih jedinica nepravilnih polimera).

\section{PIP-1 NAČELA IMENOVANJA POLIMERA NA OSNOVI STRUKTURE}

Načela imenovanja polimera na osnovi strukture za pravilne i nepravilne polimere opisana su prije, ${ }^{2,5,9,10}$ a sažeti prikazi dani su u tri dokumenta. ${ }^{11-13}$ Ovisno o poznavanju strukturnih pojedinosti, ime polimera na osnovi strukture je dugačko, a primjena pravila imenovanja organske kemije u imenovanju polimera može biti zamorno. Primjeri se mogu naći u IUPAC-ovim preporukama imenovanja cikličkih makromolekula. ${ }^{10}$

Pravilni polimer tvore makromolekule izgrađene ponavljanjem istovrsnih konstitucijskih jedinica povezanih na isti način s obzirom na smjer povezivanja. ${ }^{5}$ Za većinu pravilnih 
polimera prihvaćene su idealizirane strukture, a zanemarene nepravilnosti.

Konstitucijska jedinica (KJ) je atom ili skupina atoma (zajedno s bočnim atomima ili skupinama, ako postoje) koja čini bitan dio strukture makromolekule, oligomerne molekule, bloka ili lanca. ${ }^{5}$

Ponavljana konstitucijska jedinica (PKJ) je najmanja konstitucijska jedinica čije ponavljanje tvori pravilnu makromolekulu, pravilnu oligomernu molekulu, pravilni blok ili pravilni lanac. $^{5}$

Pri imenovanju pravilnih polimera na osnovi strukture upotrebljava se ime preferentnog PKJ-a, a to se određuje na sljedeći način:

(i) napiše se dovoljno dug segment polimernoga lanca kako bi se vidjelo ponavljanje strukture, npr.<smiles>COCC(Br)OCC(Br)OCC(C)Br</smiles>

(ii) pronađeni najmanji ponavljani dio je PKJ-a, pri čemu su sagledane sve mogućnosti u oba smjera, za navedeni primjer su:<smiles>CCOC(C)Br</smiles><smiles>CCC(Br)OC</smiles><smiles>COCC(C)Br</smiles><smiles>CCOC(C)Br</smiles><smiles>CCC(Br)OC</smiles><smiles>COCC(C)Br</smiles>

(iii) sljedeći je korak utvrditi podjedinice koje tvore svaku od tih struktura, tj. najveće skupine koje se mogu imenovati prema IUPAC-ovom imenovanju organske kemije ili (kada je to primjereno) anorganske kemije,

(iv) odredi se točan redoslijed podjedinica prema opadajućoj seniornosti, a ako je potrebno i daljnji odabir,

(v) preferentni PKJ-i odabiru se kao oni s najmanjim mogućim lokantom (lokantima) supstituenta (supstituenata).

Uobičajeno se preferentni PKJ polimera piše navođenjem njegovih podjedinica opadajućim redom seniornosti s lijeva nadesno, tj. za navedeni primjer:<smiles>CCC(Br)OC</smiles>

$\mathrm{U}$ skladu s imenima $\mathrm{KJ}$-a navedenih pod rednim brojevima 152 i 29 u tablici 1, ime polimera će biti poli[oksi(1-brometilen)].

Treba naglasiti da točno ime preferentnog PKJ-a ne ovisi o tome kako je formula napisana:

$$
\left.\left.\underset{\mathrm{O}}{\mathrm{fNH}-\mathrm{C}}-\left[\mathrm{CH}_{2}\right]_{5}\right]_{n} \quad \text { i } \underset{\mathrm{O}}{\mathrm{C}}-\left[\mathrm{CH}_{2}\right]_{5}-\mathrm{NH}\right]_{n}
$$

Obje su strukture točno prikazane, a točno ime obiju struktura je poli[azandiil(1-oksoheksan-1,6-diil)] dobiveno pri- mjenom gore navedenih pravila određivanja PKJ-a i imena pod rednim brojevima 159 i 93 u tablici 1.

Nepravilni se polimeri sastoje od makromolekula čiju strukturu tvori ponavljanje više od jedne vrste konstitucijskih jedinica ili od makromolekula čiju strukturu tvore konstitucijske jedinice koje nisu sve jednako vezane u smjeru povezivanja. ${ }^{5}$

Nepravilni se polimeri imenuju stavljanjem prefiksa "poli" ispred imena konstitucijskih jedinica na osnovi strukture, imena se stavljaju u zagrade, a međusobno odjeljuju kosim crtama.

Jednostavan primjer nepravilnoga polimera je polimer dobiven od kloretena čije su jedinice vezane smjerom "glava-rep" i "glava-glava":<smiles>CC(Cl)CC(Cl)CCC(Cl)C(Cl)CCC(Cl)CC(Cl)Cl</smiles>

Konstitucijske jedinice su:<smiles>CC(Cl)CCC(C)Cl</smiles>

Ime polimera je poli[(1-kloretilen)/(2-kloretilen)] prema imenima KJ-a pod rednim brojevima 32 i 33 u tablici 1. Pojedinosti imenovanju nepravilnih polimera na osnovi strukture opisane su u lit. ${ }^{9}$

\section{PIP-2 KONSTITUCIJSKE JEDINICE ZA IMENOVANJE POLIMERA}

Popis konstitucijskih jedinica (KJ) u tablici 1 predstavlja $\mathrm{KJ}$-e za imenovanje uobičajenih polimera (komercijalnih ili dobro poznatih) i KJ-e koji su utvrđeni i prikupljeni u IUPAC-ovim dokumentima o imenju i nazivlju polimera. Tablica 1 sadržava kemijsku formulu svakog KJ-a i njegovo preferentno ime, koje bi se trebalo upotrijebiti pri imenovanju polimera. Stupac u tablici 1 pod nazivom "druga prihvatljiva imena KJ-a" sadržava prihvatljiva alternativna imena, a u stupcu desno od njega navedena su imena KJ-a koja se više ne bi trebalo upotrebljavati jer su zastarjela, nejasna ili iz različitih razloga netočna. Primjeri su:

- promjena preporuka koje se odnose na položaj lokanata u imenu, npr. "but-1-en-1,4-diil" umjesto "1-buten-1,4-diil";

- upotreba supstituiranoga "etilen" umjesto alkan-1,2-diil, npr. "1-metiletilen" umjesto "propan-1,2-diil";

- prijašnja upotreba za različite strukture, npr. propilen.

Formule u tablici 1 pisane su s "otvorenim" vezama slobodnih valencija kako je i uobičajeno u polimernoj kemiji gdje se kemijski simboli atoma prikazuju sa slobodnim valencijama. Okomita valovita linija na kraju svake vezne crte označava slobodnu valenciju konstitucijske jedinice i upotrebljava se u skladu s lit. ${ }^{22}$ u slučaju kad nije prikazan kemijski simbol atoma sa slobodnom valencijom u tom $\mathrm{KJ}-\mathrm{u}$. 
Imena konstitucijskih jedinica koja se i inače navode u zagradama (supstituirane podjedinice) i u tablici su u zagradama. Konstitucijske jedinice koje u tablici 1 nisu u zagradama ne stavljaju se u zagrade niti u imenima polimera, osim ako ona tvore jedan cjelovit PKJ.

Kako bi čitatelj lakše našao pojedini KJ njihova imena, KJ-i su u tablici 1 poredani u šest skupina i to:

1. ugljikovi lanci prema broju atoma u lancu i stupnju nezasićenosti,

2. ugljikovi prstenovi prema veličini prstena i stupnju nezasićenosti,

3. lanci koji sadržavaju heteroatome,

4. heterocikli prema veličini prstena te broju i vrsti heteroatoma,

5. spiro-jedinice,

6. jedinice s povezivošću većom od dva.

Stavke su unutar tih skupina poredane po rastućoj složenosti (nesupstituirane, mono- $\mathrm{i}$ višesupstituirane, broj i veličina prstenova). Strukturne su formule u većini slučajeva napisane padajućim redom seniornosti podjedinica kao što se pojavljuju u preferentnom PKJ-u (vidi PIP-1) čitajući s lijeva nadesno. U nekim će se primjerima (kao što su npr. blokovi vezani jedan na drugog na poseban način ili jedna povezujuća konstitucijska jedinica ili nepravilni polimeri) pojaviti drugačiji redoslijed ili orijentacija konstitucijskih jedinica, pa će se to odraziti na ime odgovarajućeg KJ-a u imenu polimera. Imena koja odstupaju od imena preferentnog PKJ-a (ako se polimer sastoji samo od takvih KJ-a) navedena su u primjerima 33 i 76 u tablice 1.

Razlozi zašto neki KJ-i nisu više prihvatljivi dani su u odgovarajućem stupcu tablice ili objašnjeni u napomenama na kraju tablice.

U tablicama 1 i 2 (ali ne i u ostatku dokumenta), zbog ograničenoga formata stupaca, upotrijebljen je simbol jednako (=) za rastavljanje predugih imena, ako ime odgovarajuće spojnice ne sadržava. Taj simbol pokazuje: a) da se ime nastavlja u sljedećem retku, b) da simbol iz imena nestaje kada se ime ne rastavlja na tom položaju na kraju retka i c) da na tom položaju u imena nema razmaka. Treba upozoriti da se pri uobičajenome rastavljanju riječi u tisku upotrebljava spojnica (-). U ovom dokumentu simbol jednako (=) upotrijebljen je samo radi jasnijeg prikaza navoda u tablicama i ne odnosi se na dvostruke veze u kemijskim formulama.

Tablica 1 - Strukture, preferentna imena, druga prihvatljiva imena i neprihvatljiva imena konstitucijskih jedinica $(\mathrm{KJ})$ za imenovanje polimera

\begin{tabular}{|c|c|c|c|c|c|}
\hline Br. & $\begin{array}{l}\text { Kemijska } \\
\text { struktura KJ-a }\end{array}$ & Preferentna imena KJ-a* & $\begin{array}{l}\text { Druga prihvatljiva } \\
\text { imena KJ-a* }\end{array}$ & $\begin{array}{l}\text { Neprihvatljiva imena } \\
\text { KJ-a* i objašnjenja }\end{array}$ & $\begin{array}{l}\text { Dokum., } \\
\text { lit. }\end{array}$ \\
\hline 1 & $-\mathrm{CH}_{2}-$ & metilen & metandiil & & $1,2,10,13-15$ \\
\hline 2 & $-\mathrm{CH}=\mathrm{ili}=\mathrm{CH}-$ & metanililiden & & $\begin{array}{l}\text { metilidina, }^{\mathrm{a}, \mathrm{b}} \\
\text { metililiden }\end{array}$ & $2,10,14$ \\
\hline 3 & $\begin{array}{rl} & \mathrm{NH}_{2} \\
-\mathrm{P} & \mathrm{H}- \\
\mathrm{H}\end{array}$ & (aminometilen) & & & 10 \\
\hline 4 & $\begin{array}{rl} & \mathrm{Br} \\
-\mathrm{I} & \mathrm{C}- \\
\mathrm{H}\end{array}$ & (brommetilen) & & & 10 \\
\hline 5 & $\begin{array}{rl} & \mathrm{Cl} \\
-\mathrm{I} & \mathrm{C}- \\
\mathrm{H} & \end{array}$ & (klormetilen) & & & $1,9,10$ \\
\hline 6 & $\begin{array}{c}\mathrm{OCH}_{3} \\
\mathrm{I}=\mathrm{O} \\
\mathrm{I}=\mathrm{C} \\
\mathrm{C}_{2} \mathrm{H}_{2} \\
-\mathrm{C}- \\
\mathrm{H}\end{array}$ & $\begin{array}{c}\text { [(2-metoksi-2-oksoetil) } \\
\text { metilen] }\end{array}$ & $\begin{array}{c}\{[(\text { metoksikarbonil })= \\
\text { metil }] \text { metilen }\}\end{array}$ & $\begin{array}{c}{[2-(\text { metoksikarbonil })=} \\
\text { etiliden }]^{\mathrm{b}, \mathrm{c}}\end{array}$ & 1 \\
\hline 7 & $\begin{aligned} & \mathrm{CH}_{3} \\
- & \stackrel{\mathrm{C}}{\mathrm{H}}-\end{aligned}$ & (metilmetilen) & & $\begin{array}{l}\text { etiliden }{ }^{\mathrm{b}, \mathrm{c}} ; \\
\text { etan-1,1-diil }^{\mathrm{c}}\end{array}$ & $1,2,10,14$ \\
\hline 8 & $\begin{aligned} & \mathrm{C}_{3} \mathrm{H}_{7} \\
&- \stackrel{\mathrm{C}}{\mathrm{C}}- \\
& \mathrm{H}\end{aligned}$ & (propilmetilen) & & $\begin{array}{l}\text { butan-1,1-diilc; } \\
\quad \text { butiliden }{ }^{\mathrm{b}, \mathrm{c}}\end{array}$ & 2 \\
\hline 9 & $-\mathrm{C}-$ & (fenilmetilen) & & benziliden ${ }^{\mathrm{b}, \mathrm{c}}$ & $1,2,10,16$ \\
\hline 10 & $\begin{aligned} & \mathrm{CCl}_{3} \\
- & \stackrel{\mathrm{C}}{\mathrm{H}}-\end{aligned}$ & [(triklormetil)metilen] & & & 17 \\
\hline
\end{tabular}




\begin{tabular}{|c|c|c|c|c|c|}
\hline $\mathrm{Br}$. & $\begin{array}{l}\text { Kemijska } \\
\text { struktura KJ-a }\end{array}$ & Preferentna imena KJ-a* & $\begin{array}{l}\text { Druga prihvatljiva } \\
\text { imena KJ-a* }\end{array}$ & $\begin{array}{l}\text { Neprihvatljiva imena } \\
\text { KJ-a* i objašnjenja }\end{array}$ & $\begin{array}{l}\text { Dokum., } \\
\text { lit. }\end{array}$ \\
\hline 11 & $-\underset{\mathrm{H}}{-\mathrm{C}}-$ & $\begin{array}{c}\{[3 \text { (trifluormetil)fenil }]= \\
\text { metilen }\}\end{array}$ & & & 2 \\
\hline 12 & $\begin{array}{l}\mathrm{Cl} \\
-\stackrel{\mathrm{l}}{\mathrm{C}}- \\
\mathrm{Cl}\end{array}$ & (diklormetilen) & & & 9 \\
\hline 13 & $\begin{array}{r}\mathrm{F} \\
\mathrm{I} \\
-\mathrm{C}- \\
\mathrm{I} \\
\mathrm{F}\end{array}$ & (difluormetilen) & & $\begin{array}{l}\text { tetrafluoretilen; } \\
\text { (1,1-difluormetilen) }\end{array}$ & $1,2,13,15$ \\
\hline 14 & $\begin{array}{r}\mathrm{CH}_{3} \\
-\stackrel{\mathrm{I}}{\mathrm{C}}- \\
\stackrel{\mathrm{I}}{\mathrm{C}} \mathrm{H}_{3}\end{array}$ & (dimetilmetilen) & & $\begin{array}{c}\text { izopropiliden }{ }^{\mathrm{b}, \mathrm{c}} ; \\
\text { propan-2,2-diilc; } \\
\text { 1-metiletan-1,1-diilc }\end{array}$ & $2,13,14,18$ \\
\hline 15 & $\begin{array}{r}\mathrm{CF}_{3} \\
-\stackrel{\mathrm{C}}{\mathrm{C}}- \\
\mathrm{I}_{\mathrm{CF}}\end{array}$ & [bis(trifluormetil)metilen] & & & 14 \\
\hline 16 & $\begin{aligned} & \mathrm{C}_{6} \mathrm{H}_{5} \\
- & \stackrel{C_{C}-}{\mathrm{I}}- \\
& { }_{\mathrm{C}} \mathrm{H}_{5}\end{aligned}$ & (difenilmetilen) & & & 2 \\
\hline 17 & $\begin{aligned} & \mathrm{CH}_{2} \\
&- \stackrel{\mathrm{C}}{\mathrm{C}}- \\
&\end{aligned}$ & (metilidenmetilen) & & $\begin{array}{l}\text { viniliden }^{\mathrm{b}, \mathrm{c}, \mathrm{d}} \\
\text { eten-1,1-diil }^{\mathrm{c}}\end{array}$ & 2 \\
\hline 18 & $\begin{aligned} & \stackrel{\mathrm{NH}}{I I}- \\
- & \mathrm{C}-\end{aligned}$ & karboimidoil & (iminometilen) & iminokarbonile & 2,9 \\
\hline 19 & 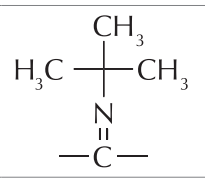 & (tert-butilkarboimidoil) & [(tert-butilimino)metilen] & & 17 \\
\hline 20 & $-\mathrm{C}-$ & $\begin{array}{l}\text { [(4-tert-butilfenil) } \\
\text { karboimidoil] }\end{array}$ & $\begin{array}{c}\{[(4-\text { tert-butilfenil)imino }] \\
\text { metilen }\}\end{array}$ & & 14 \\
\hline 21 & $\begin{array}{r}\mathrm{S} \\
-\stackrel{11}{\mathrm{C}}-\end{array}$ & karbotioil & tiokarbonil & & 1,2 \\
\hline 22 & $\begin{aligned} & \mathrm{O} \\
&- \stackrel{1}{\mathrm{C}}- \\
&\end{aligned}$ & karbonil & & & $1,2,10,14,16$ \\
\hline 23 & $-\mathrm{CH}_{2}-\mathrm{CH}_{2}-$ & etilen & etan-1,2-diil & & 2 \\
\hline 24 & $\begin{array}{c}-\mathrm{C}=\mathrm{C}- \\
\mathrm{H} \mathrm{H}\end{array}$ & eten-1,2-diil & & vinilen & $1,2,10,13,14$ \\
\hline 25 & $=c=c<$ & etentetrail & & $\begin{array}{c}\text { etendiiliden }^{\mathrm{b}} \\
\text { (samo } \mathrm{za}=\mathrm{C}=\mathrm{C}=\text { ) }\end{array}$ & 10 \\
\hline 26 & $=\underset{\mathrm{H}}{\mathrm{C}-\mathrm{C}}=$ & etandiiliden & & & 2,10 \\
\hline 27 & $-\mathrm{C} \equiv \mathrm{C}-$ & etindiil & & etin-1,2-diil & 14 \\
\hline 28 & $\begin{array}{l}\stackrel{\mathrm{H}}{\mathrm{C}}-\mathrm{CH}_{2}- \\
\mathrm{I} \\
\mathrm{I} \\
\mathrm{C}=\mathrm{O} \\
\stackrel{\mathrm{I}}{\mathrm{C}} \mathrm{H}_{3}\end{array}$ & (1-acetoksietilen) & $\begin{array}{l}\text { (1-acetoksietan-1,2-diil); } \\
\text { [1-(acetoksi)etan-1,2-diil] }\end{array}$ & & $1,2,9,13,15$ \\
\hline 29 & $\begin{array}{l}\stackrel{\mathrm{H}}{\mathrm{C}}-\mathrm{CH}_{2}- \\
\mathrm{Br}\end{array}$ & (1-brometilen) & (1-brometan-1,2-diil) & & $1,2,13$ \\
\hline
\end{tabular}




\begin{tabular}{|c|c|c|c|c|c|}
\hline Br. & $\begin{array}{l}\text { Kemijska } \\
\text { struktura KJ-a }\end{array}$ & Preferentna imena KJ-a* & $\begin{array}{l}\text { Druga prihvatljiva } \\
\text { imena KJ-a* }\end{array}$ & $\begin{array}{l}\text { Neprihvatljiva imena } \\
\text { KJ-a* i objašnjenja }\end{array}$ & $\begin{array}{l}\text { Dokum., } \\
\text { lit. }\end{array}$ \\
\hline 30 & $\begin{aligned} & \stackrel{\mathrm{H}}{\mathrm{C}}-\mathrm{CH}_{2}- \\
= & =\end{aligned}$ & (1-karbamoiletilen) & (1-karbamoiletan-1,2-diil) & & 18 \\
\hline 31 & $\begin{array}{c}\stackrel{\mathrm{H}}{\mathrm{C}}-\mathrm{CH}_{2}- \\
\stackrel{\mathrm{I}}{\mathrm{C}} \mathrm{H}_{2} \\
\mathrm{Me}_{2} \mathrm{~N}^{+}-\mathrm{CH}_{2}-\mathrm{COO}^{-}\end{array}$ & $\begin{array}{c}(1-\{[(\text { karboksilatometil })= \\
\text { dimetilazanijil }] \text { metil }\}= \\
\text { etilen })\end{array}$ & $\begin{array}{c}(1-\{[(\text { karboksilatometil })= \\
\text { dimetilamonio]metil }\} \\
\text { etilen); } \\
(1-\{[(\text { karboksilatometil })= \\
\text { dimetilamonio]metil }\} \\
\text { etan-1,2-diil })\end{array}$ & & 14 \\
\hline 32 & $-\stackrel{\mathrm{H}}{\mathrm{C}}-\mathrm{CH}_{2}-$ & (1-kloretilen) & (1-kloretan-1,2-diil) & & $\begin{array}{c}1,2,9,10,13 \\
15,18\end{array}$ \\
\hline 33 & $-\mathrm{CH}_{2}-\stackrel{\mathrm{H}}{\mathrm{C}}-$ & (2-kloretilen) & (2-kloretan-1,2-diil) & $\begin{array}{l}\text { preferentna PKJ } \\
\text { homopolimera: } \\
\text { (1-kloretilen) }\end{array}$ & 9 \\
\hline 34 & 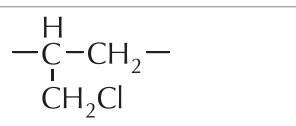 & [1-(klormetil)etilen] & [1-(klormetil)etan-1,2-diil] & & 13 \\
\hline 35 & $\begin{aligned} & \stackrel{\mathrm{H}}{\mathrm{C}}-\mathrm{CH}_{2}- \\
& \stackrel{\mathrm{I}}{\mathrm{C}} \mathrm{N}\end{aligned}$ & (1-cijanoetilen) & (1-cijanoetan-1,2-diil) & & $1,2,9,13,15$ \\
\hline 36 & $-\mathrm{CH}_{2}-\stackrel{\mathrm{H}}{\mathrm{C}}-$ & (2-cijanoetilen) & (2-cijanoetan-1,2-diil) & & 9 \\
\hline 37 & $\begin{array}{l}-\stackrel{\mathrm{H}}{\mathrm{C}}-\mathrm{CH}_{2}- \\
\quad\left[\mathrm{CH}_{2}\right]_{9}-\mathrm{CH}_{3}\end{array}$ & (1-deciletilen) & (1-deciletan-1,2-diil) & dodekan-2,1-diilc & 2 \\
\hline 38 & $\begin{array}{l}\stackrel{\mathrm{H}}{\mathrm{C}}-\mathrm{CH}_{2}- \\
\mathrm{I}\end{array}$ & (1-fluoretilen) & (1-fluoretan-1,2-diil) & & $1,2,13$ \\
\hline 39 & $\begin{array}{l}-\stackrel{\mathrm{H}}{\mathrm{C}}-\mathrm{CH}_{2}- \\
\stackrel{\mathrm{O}}{\mathrm{O}} \mathrm{H}\end{array}$ & (1-hidroksietilen) & (1-hidroksietan-1,2-diil) & & $1,2,9,13$ \\
\hline 40 & $-\stackrel{\mathrm{H}}{\mathrm{C}}-\mathrm{CH}_{2}$ & (1-jodetilen) & (1-jodetan-1,2-diil) & & 1 \\
\hline 41 & $\begin{aligned}-\mathrm{H} & \stackrel{\mathrm{C}}{\mathrm{I}}-\mathrm{CH}_{2}- \\
& \stackrel{\mathrm{C}}{\mathrm{C}} \mathrm{H}_{3}\end{aligned}$ & (1-metiletilen) & (1-metiletan-1,2-diil) & $\begin{array}{c}\text { propilenc }^{\mathrm{c}} ; \\
\text { propan-2,3-diil }^{\mathrm{c}}\end{array}$ & $\begin{array}{c}1,2,10,13-15, \\
19\end{array}$ \\
\hline 42 & $-\mathrm{CH}_{2}-\stackrel{\mathrm{H}}{\mathrm{C}}-$ & (2-metiletilen) & (2-metiletan-1,2-diil) & $\begin{array}{c}\text { preferentna PKJ } \\
\text { homopolimera: } \\
\text { (1-metiletilen) }\end{array}$ & 2 \\
\hline 43 & $\begin{array}{l}-\stackrel{\mathrm{H}}{\mathrm{C}}-\mathrm{CH}_{2}- \\
{ }_{\mathrm{O}}^{7}\end{array}$ & [1-(oksiranil)etilen] & $\begin{array}{c}\text { [1-(oksiranil)etan-1,2-diil]; } \\
\text { [1-(oksiran-2-il)etan-1,2- } \\
\text {-diil] }\end{array}$ & & 18 \\
\hline 44 & $\begin{aligned}-\stackrel{\mathrm{H}}{\mathrm{C}}-\mathrm{CH}_{2}- \\
\stackrel{\mathrm{I}}{\mathrm{COO}}{ }^{-} \mathrm{Na}^{+}\end{aligned}$ & $\begin{array}{c}\text { (natrijev } \\
1-\text { karboksilatoetilen) }\end{array}$ & $\begin{array}{c}\text { (natrijev karboksilatoetan- } \\
\text {-1,2-diil) }\end{array}$ & & 1,2 \\
\hline 45 & $-\stackrel{\mathrm{H}}{\mathrm{C}}-\mathrm{CH}_{2}-$ & (1-feniletilen) & (1-feniletan-1,2-diil) & $\begin{array}{l}\text { benzilidenmetilen }{ }^{\mathrm{c}, \mathrm{f}} ; \\
1 \text {-fenildimetilen }\end{array}$ & $\begin{array}{c}1,2,9,13-15 \\
18,20\end{array}$ \\
\hline 46 & $-\mathrm{CH}_{2}-\mathrm{C}_{-}^{\mathrm{H}}-$ & (2-feniletilen) & (2-feniletan-1,2-diil) & $\begin{array}{c}\text { preferentna PKJ } \\
\text { homopolimera: } \\
\text { (1-feniletilen) }\end{array}$ & 9 \\
\hline
\end{tabular}




\begin{tabular}{|c|c|c|c|c|c|}
\hline Br. & $\begin{array}{l}\text { Kemijska } \\
\text { struktura KJ-a }\end{array}$ & Preferentna imena KJ-a* & $\begin{array}{l}\text { Druga prihvatljiva } \\
\text { imena KJ-a* }\end{array}$ & $\begin{array}{l}\text { Neprihvatljiva imena } \\
\text { KJ-a* i objašnjenja }\end{array}$ & $\begin{array}{l}\text { Dokum., } \\
\text { lit. }\end{array}$ \\
\hline 47 & $\begin{aligned}-\stackrel{\mathrm{H}}{\mathrm{C}}-\mathrm{CH}_{2}- \\
\stackrel{\mathrm{I}}{\mathrm{C}} \mathrm{H} \\
\stackrel{\stackrel{\mathrm{C}}{\mathrm{C}} \mathrm{H}_{2}}{ }\end{aligned}$ & (1-eteniletilen) & $\begin{array}{l}\text { (1-viniletilen); } \\
\text { (1-eteniletan-1,2-diil); } \\
\text { (1-viniletan-1,2-diil) }\end{array}$ & & $\begin{array}{c}9,13,14 \\
18,19\end{array}$ \\
\hline 48 & $-\mathrm{CH}_{11}^{\mathrm{C}}-\mathrm{CH}_{2}-$ & (1-benzilidenetilen) & $\begin{array}{l}\text { [1-(fenilmetiliden)etilen]; } \\
\text { [1-(fenilmetiliden)etan- } \\
\text {-1,2-diil] }\end{array}$ & & 14 \\
\hline 49 & $\begin{aligned} \mathrm{CH}_{2}- & \stackrel{\mathrm{H}}{\mathrm{C}}- \\
& {\left[\mathrm{CH}_{2}\right]_{3} \cdot \mathrm{CH}_{3} }\end{aligned}$ & (2-butiletilen) & (2-butiletan-1,2-diil) & & 1,2 \\
\hline 50 & 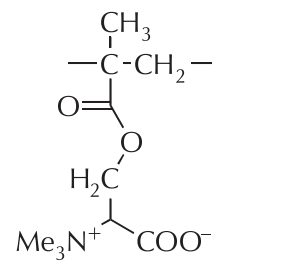 & $\begin{array}{c}(1-\{[2-k a r b o k s i l a t o-2- \\
\text {-(trimetilazanijil)etoksi] }= \\
\text { karbonil }\}-1-\text { metiletilen })\end{array}$ & $\begin{array}{c}(1-\{[2-\text { karboksilato-2- } \\
\text {-(trimetilamonio)etoksi }]= \\
\text { karbonil }\}-1-\text { metiletilen); } \\
(1-\{[2-\text { karboksilato-2- } \\
\text {-(trimetilamonio)etoksi }]= \\
\text { karbonil }\}-1 \text {-metiletan- } \\
-1,2-\text { diil })\end{array}$ & & 14 \\
\hline 51 & $\begin{array}{rl} & \mathrm{Cl} \\
-\mathrm{l} & \mathrm{C} \\
\mathrm{C} & -\mathrm{CH}_{2}-\end{array}$ & (1,1-dikloretilen) & (1,1-dikloretan-1,2-diil) & & 1 \\
\hline 52 & $\begin{aligned} & \mathrm{CH}_{3} \\
- & \stackrel{\mathrm{C}}{\mathrm{C}}-\mathrm{CH}_{2}- \\
& \stackrel{\mathrm{CN}}{ }\end{aligned}$ & (1-cijano-1-metiletilen) & $\begin{array}{c}\text { (1-cijano-1-metiletan- } \\
\text {-1,2-diil) }\end{array}$ & & 1,16 \\
\hline 53 & $\begin{array}{l}\mathrm{F} \\
-\underset{\mathrm{I}}{\mathrm{C}}-\mathrm{CH}_{2}- \\
\mathrm{F}\end{array}$ & (1,1-difluoretilen) & (1,1-difluoretan-1,2-diil) & & $1,13,15,19$ \\
\hline 54 & $\begin{aligned} & \mathrm{CH}_{3} \\
-\mathrm{I} & -\mathrm{CH}_{2}- \\
& \stackrel{\mathrm{C}}{\mathrm{C}} \mathrm{H}_{3}\end{aligned}$ & (1,1-dimetiletilen) & (1,1-dimetiletan-1,2-diil) & izobutilen & $1,2,13-16$ \\
\hline 55 & $\stackrel{\mathrm{C}}{\mathrm{C}}-\mathrm{CH}_{3}-$ & $\begin{array}{l}\text { [1-(metoksikarbonil)- } \\
\text {-1-metiletilen] }\end{array}$ & $\begin{array}{l}\text { [1-(metoksikarbonil)-1- } \\
\text {-metiletan-1,2-diil] }\end{array}$ & & $1,9,13$ \\
\hline 56 & $-\underset{\mathrm{O}}{\mathrm{C}}-\mathrm{CH}_{2}-$ & (1-oksoetilen) & (1-oksoetan-1,2-diil) & & 16 \\
\hline 57 & $-\stackrel{\mathrm{H}}{\mathrm{C}}-\stackrel{\mathrm{O}}{\mathrm{C}}-$ & (1-klor-2-oksoetilen) & (1-klor-2-oksoetan-1,2-diil) & & 1,2 \\
\hline 58 & 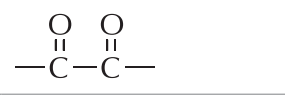 & oksalil & $\begin{array}{c}\text { etandioil; } \\
\text { 1,2-dioksoetan-1,2-diil }\end{array}$ & & 1,2 \\
\hline 59 & $-\stackrel{\mathrm{Cl}}{\mathrm{C}-\mathrm{C}}-$ & (1-metiliden-2-feniletilen) & $\begin{array}{l}\text { (1-metiliden-2-feniletan- } \\
\text {-1,2-diil) }\end{array}$ & & 1,14 \\
\hline 60 & $\begin{aligned} & \mathrm{CH}_{3} \mathrm{CH}_{3} \\
&-\stackrel{\mathrm{I}}{\mathrm{C}}-\stackrel{\mathrm{H}}{\mathrm{H}}-\end{aligned}$ & (1,2-dimetiletilen) & (1,2-dimetiletan-1,2-diil) & $(\text { butan-2,3-diil })^{\mathrm{c}}$ & $2,17,19$ \\
\hline 61 & $\begin{array}{cc}\mathrm{C}_{6} \mathrm{H}_{5} \\
\mathrm{I}^{\mathrm{S}} \\
-\mathrm{I}-\mathrm{I}-\mathrm{C}- \\
\mathrm{H}-\mathrm{H}\end{array}$ & $\begin{array}{c}{[1-\text { okso-2-(fenilsulfanil })=} \\
\text { etilen }]\end{array}$ & $\begin{array}{l}\text { [1-okso-2-(fenilsulfanil) } \\
\quad \text { etan-1,2-diil] }\end{array}$ & $\begin{array}{c}\text { [1-okso-2-(feniltio) } \\
\text { etilen]; } \\
\text { [1-okso-2-(feniltio)etan- } \\
\text {-1,2-diil] }\end{array}$ & 1,2 \\
\hline
\end{tabular}




\begin{tabular}{|c|c|c|c|c|c|}
\hline Br. & $\begin{array}{l}\text { Kemijska } \\
\text { struktura KJ-a }\end{array}$ & Preferentna imena KJ-a* & $\begin{array}{l}\text { Druga prihvatljiva } \\
\text { imena KJ-a* }\end{array}$ & $\begin{array}{l}\text { Neprihvatljiva imena } \\
\text { KJ-a* i objašnjenja }\end{array}$ & $\begin{array}{l}\text { Dokum., } \\
\text { lit. }\end{array}$ \\
\hline 62 & $\begin{array}{l}\mathrm{H}_{5} \mathrm{C}_{6} \mathrm{C}_{6} \mathrm{H}_{5} \\
-\mathrm{I}=\mathrm{I}-\end{array}$ & (1,2-difenileten-1,2-diil) & & & 2 \\
\hline 63 & $-\mathrm{CH}_{2}-\mathrm{CH}_{2}-\mathrm{CH}_{2}-$ & propan-1,3-diil & & trimetilen & \\
\hline 64 & $-\mathrm{CH}=\mathrm{CH}-\mathrm{CH}=$ & prop-1-en-1-il-3-iliden & & 1-propen-1-il-3-iliden & 1,2 \\
\hline 65 & $=\mathrm{CH}-\mathrm{CH}=\mathrm{CH}-$ & prop-2-en-3-il-1-iliden & & 2-propen-3-il-1-iliden & 1,2 \\
\hline 66 & $=\mathrm{CH}-\mathrm{CH}_{2}-\mathrm{CH}=$ & propan-1,3-diiliden & & 1,3-propandiiliden & 1,2 \\
\hline 67 & $-\mathrm{CH}_{2}-\mathrm{CH}_{2}-\mathrm{CH}=$ & propan-1-il-3-iliden & & & \\
\hline 68 & $=\mathrm{CH}-\mathrm{CH}_{2}-\mathrm{CH}_{2}-$ & propan-3-il-1-iliden & & & 10 \\
\hline 69 & $-\mathrm{CH}_{2}-\mathrm{CH}_{2}-\stackrel{\mathrm{Br}}{\mathrm{C}} \mathrm{H}-$ & (3-brompropan-1,3-diil) & & (3-bromtrimetilen) & 1 \\
\hline 70 & $\begin{array}{ll}\mathrm{Br}_{\mathrm{r}} & \mathrm{Cl} \\
-\mathrm{C} & \mathrm{C}-\mathrm{CH}_{2}-\underset{\mathrm{H}}{\mathrm{C}}- \\
\mathrm{H} & \end{array}$ & $\begin{array}{c}\text { (1-brom-3-klorpropan- } \\
\text {-1,3-diil) }\end{array}$ & & 1-brom-3-klortrimetilen & 2 \\
\hline 71 & 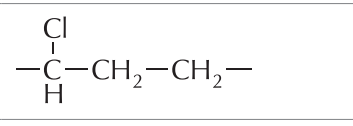 & (1-klorpropan-1,3-diil) & & 1-klortrimetilen & 1,2 \\
\hline 72 & 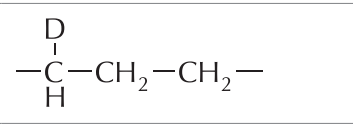 & {$\left[\left(1-{ }^{2} \mathrm{H}_{1}\right)\right.$ propan-1,3-diil] } & & trimetilen-1-d & 2 \\
\hline 73 & $-\mathrm{CH}_{2}-\stackrel{\stackrel{\mathrm{Cl}}{\mathrm{C}}}{\mathrm{H}}-\mathrm{CH}_{2}-$ & (2-klorpropan-1,3-diil) & & (2-klortrimetilen) & 1,2 \\
\hline 74 & $-\stackrel{\mathrm{OH}}{\mathrm{I}}^{\mathrm{C}} \mathrm{H}-\mathrm{CH}_{2}-$ & (2-hidroksipropan-1,3-diil) & & & 18 \\
\hline 75 & $\stackrel{\mathrm{O}}{-\mathrm{II}}-\left[\mathrm{CH}_{2}\right]_{2}-$ & (1-oksopropan-1,3-diil) & & & 18 \\
\hline 76 & $-\stackrel{\mathrm{II}}{\mathrm{C}}-\mathrm{CH}_{2}-\stackrel{\mathrm{O}}{\mathrm{C}}-$ & propandioil & $\begin{array}{c}\text { malonil; } \\
\text { (1,3-dioksopropan-1,3-diil) }\end{array}$ & $\begin{array}{c}\text { preferentna PKJ } \\
\text { homopolimera: } \\
\text { (1,2-dioksopropan- } \\
\text {-1,3-diil) }\end{array}$ & 2 \\
\hline 77 & $-\mathrm{CH}_{2}-\mathrm{CH}_{2}-\mathrm{CH}_{2}-\mathrm{CH}_{2}-$ & butan-1,4-diil & & tetrametilen & $\begin{array}{c}2,9,10,13 \\
14,18\end{array}$ \\
\hline 78 & $-\mathrm{CH}=\mathrm{CH}-\mathrm{CH}_{2}-\mathrm{CH}_{2}-$ & but-1-en-1,4-diil & & 1-butenilen & $\begin{array}{c}1,2,9,13 \\
14,18\end{array}$ \\
\hline 79 & $-\mathrm{CH}_{2}-\mathrm{CH}=\mathrm{CH}-\mathrm{CH}_{2}-$ & but-2-en-1,4-diil & & 2-butenilen & 2,9 \\
\hline 80 & $-\stackrel{\mathrm{O}}{\mathrm{C}}-\mathrm{CH}_{2}-\mathrm{CH}_{2}-\stackrel{\mathrm{II}}{\mathrm{C}}-$ & butandioil & $\begin{array}{l}\text { sukcinil; } \\
\text { (1,4-dioksobutan-1,4-diil) }\end{array}$ & $\begin{array}{c}\text { (1,2-dioksotetrametilen); } \\
\text { preferentna PKJ } \\
\text { homopolimera: } \\
\text { (1,2-dioksobutan- } \\
\text {-1,4-diil) }\end{array}$ & $1,13,14$ \\
\hline 81 & 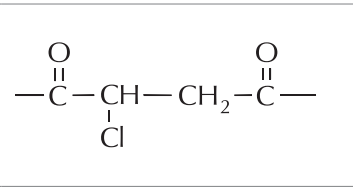 & (2-klorbutandioil) & & $\begin{array}{c}\text { (2-klorsukcinil); } \\
\text { preferentna PKJ } \\
\text { homopolimera: } \\
(1,2 \text {-diokso-3- } \\
\text {-klorbutan-1,4-diil) }\end{array}$ & 1,16 \\
\hline 82 & $\begin{array}{c}\mathrm{C}_{3} \mathrm{H}_{3} \mathrm{C}_{3} \mathrm{H}_{3} \\
-\mathrm{CH}_{2}-\mathrm{CH}-\mathrm{CH}-\mathrm{CH}_{2}-\end{array}$ & (2,3-dimetilbutan-1,4-diil) & & $\begin{array}{c}\text { preferentna PKJ } \\
\text { homopolimera: } \\
\text { (1,2-dimetilbutan- } \\
\text {-1,4-diil) }\end{array}$ & 19 \\
\hline 83 & $\stackrel{\stackrel{\mathrm{Cl}}{\mathrm{C}}=\mathrm{CH}-\mathrm{CH}_{2}-\mathrm{CH}_{2}-}{-}$ & (1-klorbut-1-en-1,4-diil) & & (1-klor-1-butenilen) & 16 \\
\hline 84 & $-\stackrel{\mathrm{CH}_{3}}{\mathrm{C}}=\mathrm{CH}-\mathrm{CH}_{2}-\mathrm{CH}_{2}-$ & (1-metilbut-1-en-1,4-diil) & & (1-metil-1-butenilen) & $1,2,13,15,19$ \\
\hline 85 & $-\mathrm{CH}=\mathrm{CH}-\stackrel{\mathrm{I}_{3}}{\mathrm{C}} \mathrm{H}-\mathrm{CH}_{2}-$ & (3-metilbut-1-en-1,4-diil) & & & 19 \\
\hline
\end{tabular}




\begin{tabular}{|c|c|c|c|c|c|}
\hline Br. & $\begin{array}{l}\text { Kemijska } \\
\text { struktura KJ-a }\end{array}$ & Preferentna imena KJ-a* & $\begin{array}{l}\text { Druga prihvatljiva } \\
\text { imena KJ-a* }\end{array}$ & $\begin{array}{l}\text { Neprihvatljiva imena } \\
\text { KJ-a* i objašnjenja }\end{array}$ & $\begin{array}{l}\text { Dokum., } \\
\text { lit. }\end{array}$ \\
\hline 86 & 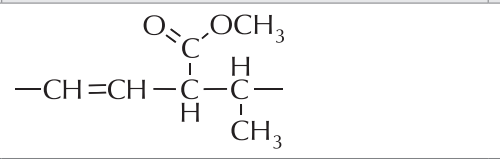 & $\begin{array}{l}\text { [3-(metoksikarbonil)- } \\
\text {-4-metilbut-1-en-1,4-diil] }\end{array}$ & & & 19 \\
\hline 87 & $-\stackrel{\mathrm{O}}{\mathrm{C}}-\mathrm{CH}=\mathrm{CH}-\stackrel{\mathrm{O}}{\mathrm{C}}-$ & butendioil & fumaroil $(E)$; maleoil $(Z)$ & & 2,14 \\
\hline 88 & $-\mathrm{CH}_{2}-\left[\mathrm{CH}_{2}\right]_{3}-\mathrm{CH}_{2}-$ & pentan-1,5-diil & & pentametilen & 2 \\
\hline 89 & 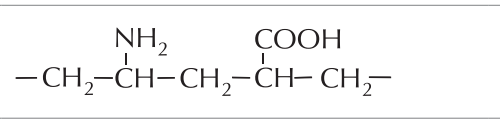 & $\begin{array}{l}\text { (2-amino-4- } \\
\text {-karboksipentan-1,5-diil) }\end{array}$ & & $\begin{array}{l}(2 \text {-amino- } 4- \\
\text {-karboksipentameti }= \\
\text { len })\end{array}$ & 1,2 \\
\hline 90 & $-\mathrm{CH}_{2}-\mathrm{CH}_{2}-\stackrel{\mathrm{I}}{\mathrm{C}} \mathrm{H}-\mathrm{CH}_{2}-\stackrel{\stackrel{\mathrm{Br}}{\mathrm{C}} \mathrm{H}-}{-}$ & $\begin{array}{l}\text { (5-brom-3-klorpentan- } \\
\text {-1,5-diil) }\end{array}$ & & $\begin{array}{c}\text { 5-brom- } \\
\text {-3-klorpentametilen); } \\
\text { preferentna PKJ } \\
\text { homopolimera: } \\
\text { (1-brom-3-klorpentan- } \\
\text {-1,5-diil) }\end{array}$ & 1,2 \\
\hline 91 & $-\stackrel{\mathrm{O}}{\mathrm{C}}-\left[\mathrm{CH}_{2}\right]_{3}-\stackrel{\mathrm{O}}{\mathrm{C}}-$ & pentandioil & $\begin{array}{c}\text { glutaril; } \\
\text { (1,5-dioksopentan-1,5-diil) }\end{array}$ & $\begin{array}{l}\text { preferentna PKJ } \\
\text { homopolimera: } \\
\text { (1,2-dioksopentan- } \\
\text {-1,5-diil) }\end{array}$ & 2 \\
\hline 92 & $-\mathrm{CH}_{2}-\left[\mathrm{CH}_{2}\right]_{4}-\mathrm{CH}_{2}-$ & heksan-1,6-diil & & heksametilen & $\begin{array}{c}1,2,9,10,13 \\
14,16,18\end{array}$ \\
\hline 93 & $-\stackrel{\mathrm{O}}{\mathrm{C}}-\left[\mathrm{CH}_{2}\right]_{5}-$ & (1-oksoheksan-1,6-diil) & & $\begin{array}{c}\text { 1-oksoheksametilen; } \\
\text { heksanoil } \\
\text { (monofunkcijski) }\end{array}$ & $1,2,13,14,20$ \\
\hline 94 & $\stackrel{\mathrm{O}}{\mathrm{II}}-\mathrm{CH}_{2}-\stackrel{\mathrm{O}}{\mathrm{C}}-\mathrm{CH}_{2}-\mathrm{CH}_{2}-\mathrm{CH}_{2}-$ & (1,3-dioksoheksan-1,6-diil) & & 1,3-dioksoheksametilen & 1,2 \\
\hline 95 & $-\stackrel{\mathrm{O}}{\mathrm{C}}-\left[\mathrm{CH}_{2}\right]_{4}-\stackrel{\mathrm{O}}{\mathrm{C}}-$ & heksandioil & $\begin{array}{c}\text { adipoil; } \\
\text { (1,6-dioksoheksan-1,6-diil) }\end{array}$ & $\begin{array}{l}\text { 1,6-dioksoheksametilen; } \\
\text { preferentna PKJ } \\
\text { homopolimera: } \\
\text { (1,2-dioksoheksan- } \\
\text {-1,6-diil) }\end{array}$ & $1,2,9,13-15$ \\
\hline 96 & $-\mathrm{CH}_{2}-\left[\mathrm{CH}_{2}\right]_{6}-\mathrm{CH}_{2}-$ & oktan-1,8-diil & & & 14 \\
\hline 97 & $-\underset{\mathrm{H} \mathrm{H}}{\mathrm{C}}=\mathrm{C}-\left[\mathrm{CH}_{2}\right]_{5}-\mathrm{CH}_{2}-$ & okt-1-en-1,8-diil & & & 10 \\
\hline 98 & $-\mathrm{C} \equiv \mathrm{C}-\left[\mathrm{CH}_{2}\right]_{5}-\mathrm{CH}_{2}-$ & okt-1-in-1,8-diil & & & 14 \\
\hline 99 & 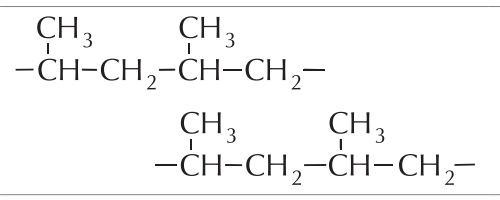 & $\begin{array}{c}(1,3,5,7 \text {-tetrametiloktan- } \\
\text {-1,8-diil) }\end{array}$ & & $\begin{array}{l}\text { za homopolimer: } \\
\text { poli(1-metiletilen) }\end{array}$ & 19 \\
\hline 100 & $-\mathrm{CH}_{2}-\left[\mathrm{CH}_{2}\right]_{8}-\mathrm{CH}_{2}-$ & dekan-1,10-diil & & & 14 \\
\hline 101 & 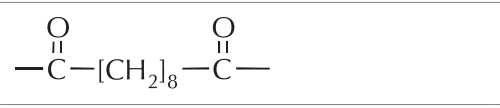 & dekandioil & 1,10-dioksodekan-1,10-diil & sebacil & $1,2,10,14$ \\
\hline 102 & $-\mathrm{CH}_{2}-\left[\mathrm{CH}_{2}\right]_{10}-\mathrm{CH}_{2}-$ & dodekan-1,12-diil & & & 14 \\
\hline 103 & 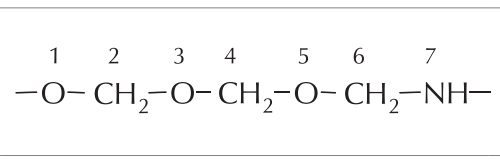 & $\begin{array}{c}\text { oksimetilenoksimetilen }= \\
\text { oksimetilenazandiil }\end{array}$ & & $\begin{array}{l}\text { (1,3,5-trioksa-7- } \\
\text {-azaheptan-1,7-diil)g; } \\
\text { (vidi oksi, metilen, } \\
\text { azandiil) }\end{array}$ & 2 \\
\hline 104 & 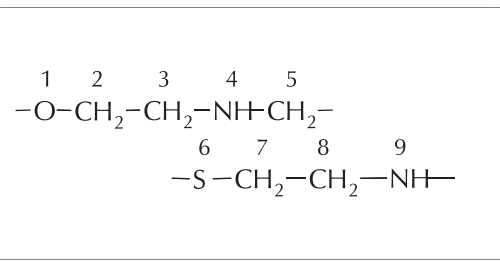 & $\begin{array}{l}\text { oksietilenazandiilmetilen }= \\
\text { sulfandiiletilenazandiil }\end{array}$ & & $\begin{array}{c}\text { (1-oksa-6-tia-4,9- } \\
\text {-diazanonan)-1,9-diil)g; } \\
\text { oksietileniminome= } \\
\text { tilentioetilenimino } \\
\text { (vidi oksi, etilen, } \\
\text { azandiil, sulfandiil, } \\
\text { metilen) }\end{array}$ & 1,2 \\
\hline
\end{tabular}


\begin{tabular}{c|l} 
Br. & $\begin{array}{l}\text { Kemijska } \\
\text { struktura KJ-a }\end{array}$ \\
& \\
$105 \stackrel{-O}{-}-\mathrm{CH}_{2}-\mathrm{O}-\mathrm{CH}_{2}-\mathrm{NH}-\mathrm{CH}_{2}-$ \\
$\quad-\mathrm{CH}_{2}-\mathrm{S}-\mathrm{CH}_{2}-\mathrm{NH}+\mathrm{CH}_{2}-\mathrm{CH}_{2}-$
\end{tabular}

$106\{\xi \xi$

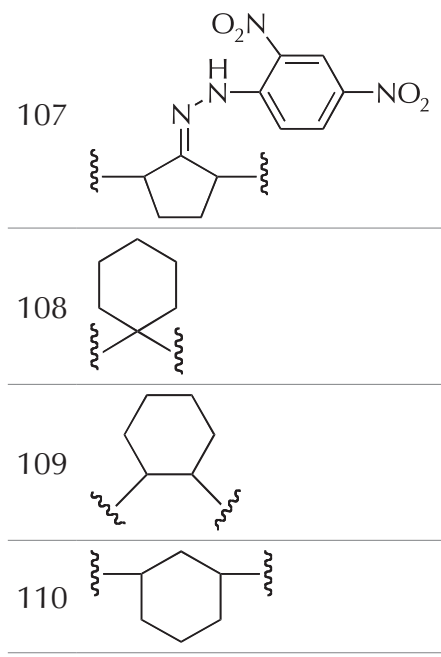

111

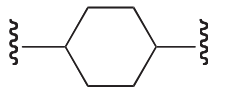

112<smiles>[CH]C1C=CCC(C)C1</smiles>

113<smiles>C=C1C=CC([Tl])C=C1</smiles>

oksimetilenoksimetilen= azandiiletilensulfandiil= metilenazandiiletilen
Druga prihvatljiva imena $\mathrm{KJ}-\mathrm{a}$ ciklopentan-1,2-diil

$\{2-[(2,4-$ dinitrofenil $)=$ hidraziniliden]ciklopentan-1,3-diil\}
Neprihvatljiva imena $\mathrm{KJ}-\mathrm{a}^{*} \mathrm{i}$ objašnjenja

(1,3-dioksa-8-tia-5,10-diazadodekan-1,12-diil); oksimetilenoksime $=$ tileniminoetilen $=$ sulfandiilmetilen $=$ iminoetilen $^{\mathrm{h}}$

\section{1,2-ciklopentilen $\quad 1,2,19$}

$\{2-[2,4-$ dinitrofenil $)=$ hidrazono]-

-1,3-ciklopentilen\};

$\{2-[(2,4-$ dinitrofenil $)=$ hidrazono]ciklo $=$ pentan-1,3-diil\}

cikloheksan-1,1-diil

cikloheksiliden ${ }^{\mathrm{b}}$

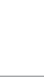

cikloheksan-1,2-diil

cikloheksan-1,3-diil

1,3-cikloheksilen

$1,2,13$

cikloheksan-1,4-diil

1,4-cikloheksilen

$1,2,16$

cikloheks-4-en-1,3-diil

4-cikloheksen-1,3-ilen

1,2

(cikloheksa-2,5-dien-1,4-diiliden)

(6-klorcikloheks-1-en-1,3-diil)

(6-klor-1-cikloheksen-1,3-ilen)

triciklo[2.2.1.0 $\left.0^{2,6}\right]$ heptan$-3,5$-diil

triciklo[2.2.1.0 $\left.0^{2,6}\right]=$ hept-3,5-ilen

115<smiles>CC1C2CC3CC1C(I)C3C2</smiles>

116<smiles>Cc1ccccc1I</smiles>

1,2-fenilen

benzen-1,2-diil

o-fenilen

13

117<smiles>Cc1cccc(I)c1</smiles>

1,3-fenilen

benzen-1,3-diil

$m$-fenilen

118<smiles>Cc1ccc(I)cc1</smiles>

1,4-fenilen

benzen-1,4-diil

p-fenilen

119<smiles>CCc1ccc(C(C)(C)C)cc1I</smiles>

120<smiles>Cc1cccc(I)c1C</smiles>

(4-tert-butilbenzen-

\section{-1,2-diil);}

[4-(1,1-dimetiletil)-

(4-tert-butil-o-fenilen)

10

-1,2-fenilen] 


\begin{tabular}{|c|c|c|c|c|c|}
\hline & $\begin{array}{l}\text { Kemijska } \\
\text { struktura KJ-a }\end{array}$ & Preferentna imena KJ-a* & $\begin{array}{l}\text { Druga prihvatljiva } \\
\text { imena KJ-a* }\end{array}$ & $\begin{array}{l}\text { Neprihvatljiva imena } \\
\text { KJ-a* i objašnjenja }\end{array}$ & $\begin{array}{l}\text { Dokum., } \\
\text { lit. }\end{array}$ \\
\hline 121 & & (4-metil-1,3-fenilen) & & & 14 \\
\hline 122 & & (4-nitro-1,3-fenilen) & & & 1,2 \\
\hline 123 & & (x-metil-1,3-fenilen) & & & 2 \\
\hline 124 & & (2-fenil-1,3-fenilen) & & 2,6-bifenilen ${ }^{c}$ & $1,2,16$ \\
\hline 125 & & (5-fenil-1,3-fenilen) & & bifenil-3,5-diilc & 2,16 \\
\hline 126 & & (2-metil-1,4-fenilen) & & & 14 \\
\hline 127 & & (2-metoksi-1,4-fenilen) & & & 14,16 \\
\hline 128 & & (2-karboksi-1,4-fenilen) & & & 14 \\
\hline 129 & & (2-klor-1,4-fenilen) & (2-klorbenzen-1,4-diil) & $(2-k l o r-p \text {-fenilen })^{j}$ & 10 \\
\hline 130 & & (3-klor-1,4-fenilen) & & $\begin{array}{c}\text { preferentna PKJ } \\
\text { homopolimera: } \\
\text { (2-klor-1,4-fenilen) }\end{array}$ & 1,2 \\
\hline 131 & & (metilfenilen) & & & 2 \\
\hline 132 & & ftaloil & $\begin{array}{l}\text { karbonil-1,2- } \\
\text { fenilenkarbonil }\end{array}$ & benzen-1,2-dikarbonili & 2,14 \\
\hline 133 & & izoftaloil & $\begin{array}{c}\text { karbonil-1,3- } \\
\text {-fenilenkarbonil }\end{array}$ & benzen-1,3-dikarbonili & 2 \\
\hline
\end{tabular}




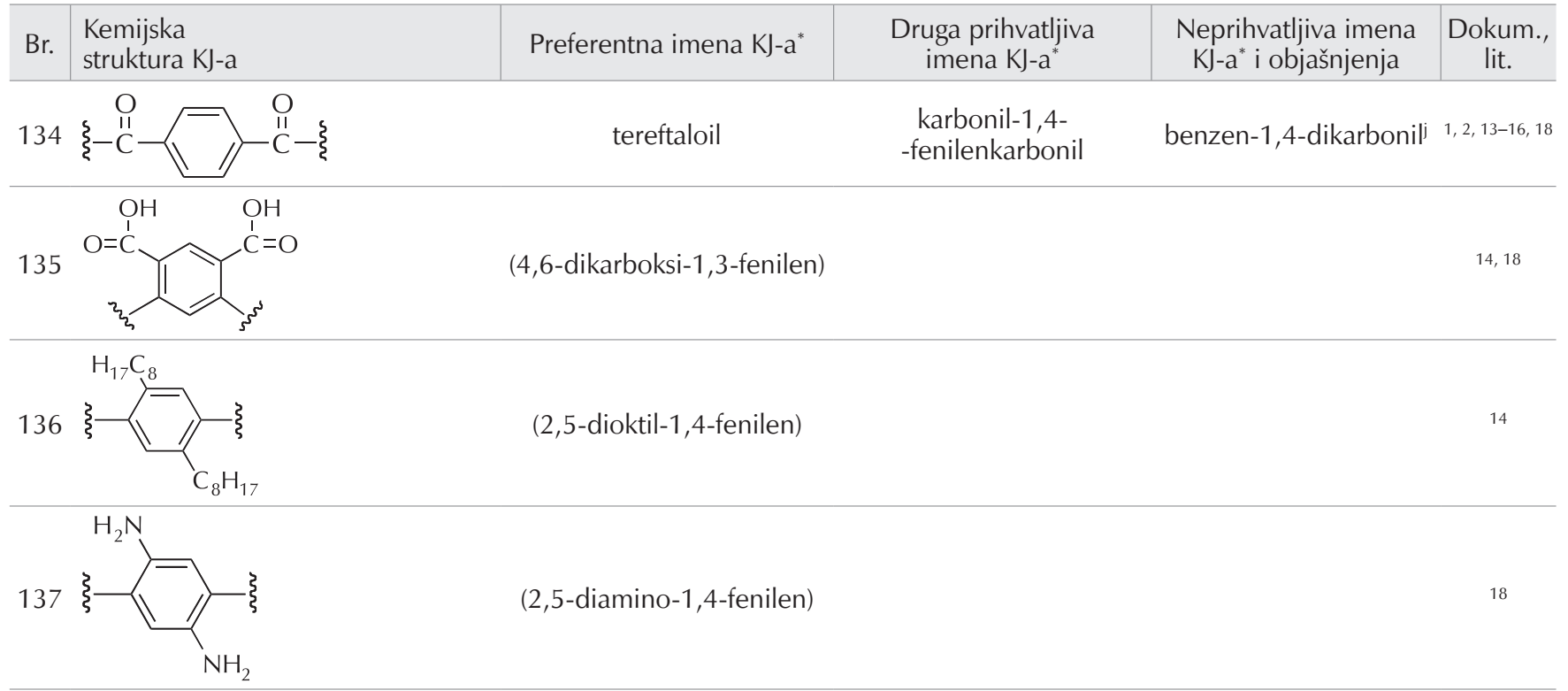

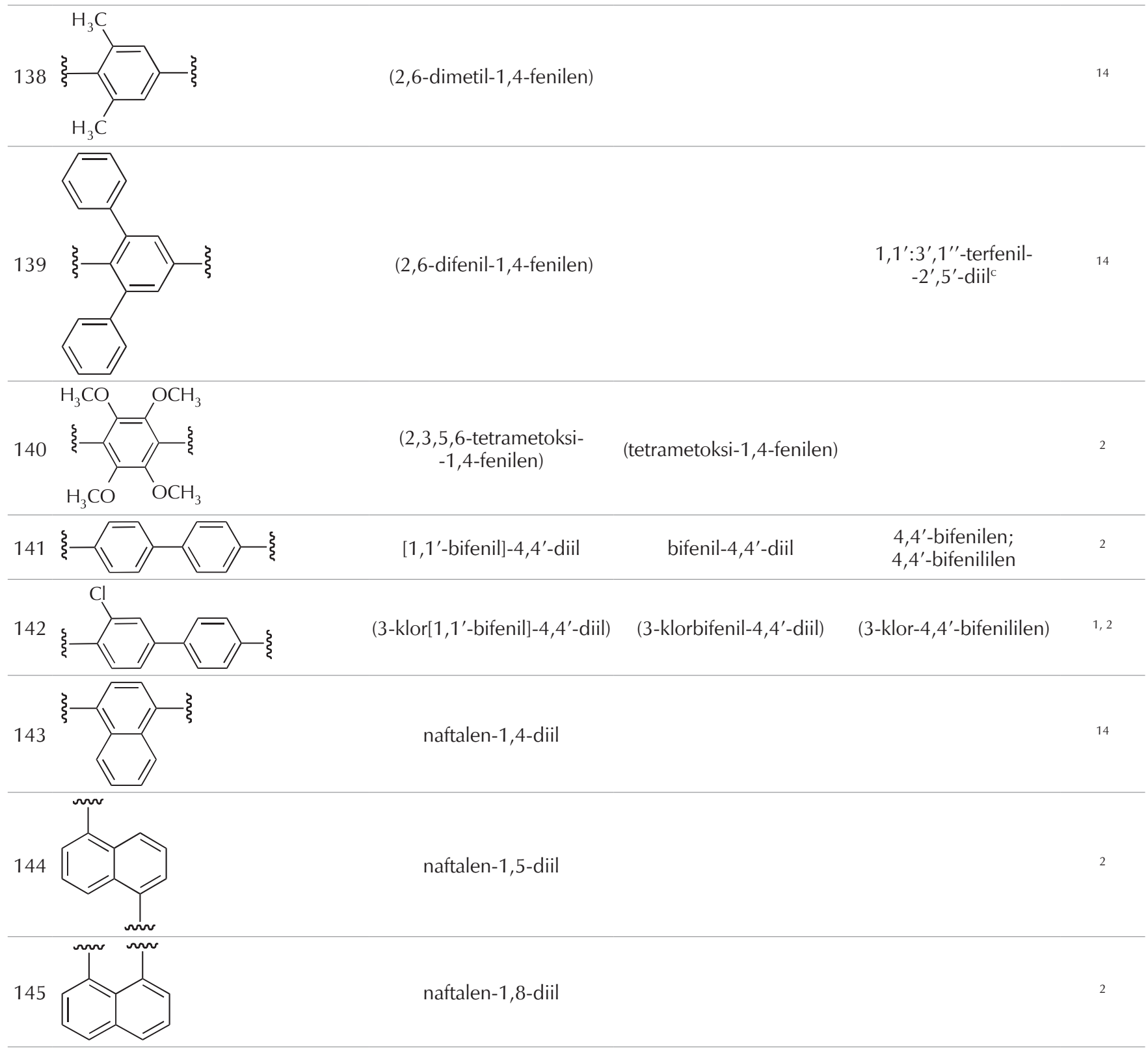




\begin{tabular}{|c|c|c|c|c|c|}
\hline Br. & $\begin{array}{l}\text { Kemijska } \\
\text { struktura KJ-a }\end{array}$ & Preferentna imena KJ-a* & $\begin{array}{l}\text { Druga prihvatljiva } \\
\text { imena } \mathrm{KJ}-\mathrm{a}^{*}\end{array}$ & $\begin{array}{l}\text { Neprihvatljiva imena } \\
\text { KJ-a* i objašnjenja }\end{array}$ & $\begin{array}{l}\text { Dokum., } \\
\text { lit. }\end{array}$ \\
\hline 146 & & naftalen-2,6-diil & & & 2 \\
\hline 147 & & naftalen-2,7-diil & & $\begin{array}{l}\text { 2,7-naftilen; } \\
\text { 2,7-naftalendiil }\end{array}$ & 1,2 \\
\hline 148 & $\xi$ & $\begin{array}{l}\text { 3'-brom-2-klor }\left[1,1^{\prime}: 4^{\prime}, 1^{\prime \prime} \text { - }\right. \\
\text {-terfenil]-4, } 4^{\prime} \text {-diil) }\end{array}$ & & $\begin{array}{l}\text { (3'-brom-2-klor- } p \text { - } \\
\text {-terfenil-4,4"'-ilen) }\end{array}$ & 1,2 \\
\hline 149 & & $\begin{array}{c}\text { (5'-klor[1, 2'-binaftalen]- } \\
\left.-4,7^{\prime} \text {-diil }\right)\end{array}$ & & $\begin{array}{c}\text { (5'-klor-1,2'-binaftil- } \\
\left.-4,7^{\prime} \text {-ilen }\right)\end{array}$ & 1,2 \\
\hline 150 & $\xi$ & acenaftilen-3,7-diil & & & 2 \\
\hline 151 & & acenaftilen-3,8-diil & & 3,8-acenaftilenilen & 1,2 \\
\hline 152 & $-\mathrm{O}-$ & oksi & & & $1,2,13,14,16$ \\
\hline 153 & $-\mathrm{O}-\mathrm{O}-$ & peroksi & & dioksi & 2 \\
\hline 154 & $-s-$ & sulfandiil & & tio & $\begin{array}{c}1,2,10,13 \\
14,16\end{array}$ \\
\hline 155 & $-S-S-$ & disulfandiil & & ditio & 2,14 \\
\hline 156 & $\begin{aligned} & \mathrm{O} \\
&- \mathrm{S}- \\
&-\end{aligned}$ & sulfinil & tionil & & 1,2 \\
\hline 157 & $\begin{array}{c}\mathrm{O} \\
\mathrm{II} \\
-\mathrm{S}- \\
\mathrm{O} \\
\mathrm{O}\end{array}$ & sulfonil & sulfuril & & $1,2,10,13,14$ \\
\hline 158 & $-\mathrm{Se}-$ & selandiil & & & 10 \\
\hline 159 & $-\stackrel{H}{\mathrm{~N}}-$ & azandiil & & imino $^{h}$ & $1,2,10,13,14$ \\
\hline 160 & $\begin{array}{r}\mathrm{OH} \\
-\mathrm{N}- \\
\end{array}$ & (hidroksiazandiil) & & $(\text { hidroksiimino })^{\mathrm{h}}$ & 2 \\
\hline 161 & $\begin{array}{r}\mathrm{CH}_{3} \\
-\stackrel{\mathrm{N}}{-}-\end{array}$ & (metilazandiil) & & $(\text { metilimino })^{\mathrm{h}}$ & $1,2,10$ \\
\hline 162 & $\begin{array}{r}\mathrm{CH}_{3} \\
\stackrel{\mathrm{C}}{\mathrm{I}} \mathrm{H}_{2} \\
-\mathrm{N}-\end{array}$ & (etilazandiil) & & $(\text { etilimino })^{\mathrm{h}}$ & 13 \\
\hline 163 & $\begin{array}{r}\mathrm{R} \\
\mathrm{l} \\
-\mathrm{N}-\end{array}$ & (alkilazandiil) & & $(\text { alkilimino })^{\mathrm{h}}$ & 14 \\
\hline 164 & $\begin{aligned} & \mathrm{C}_{6} \mathrm{H}_{5} \\
- & \mathrm{I}-\end{aligned}$ & (fenilazandiil) & & $(\text { fenilimino })^{\mathrm{h}}$ & $2,10,14$ \\
\hline
\end{tabular}




\begin{tabular}{|c|c|c|c|c|c|}
\hline $\mathrm{Br}$. & $\begin{array}{l}\text { Kemijska } \\
\text { struktura KJ-a }\end{array}$ & Preferentna imena KJ-a* & $\begin{array}{l}\text { Druga prihvatljiva } \\
\text { imena KJ-a* }\end{array}$ & $\begin{array}{l}\text { Neprihvatljiva imena } \\
\mathrm{KJ}^{*} \mathrm{a}^{*} \text { i objašnjenja }\end{array}$ & $\begin{array}{c}\text { Dokum., } \\
\text { lit. }\end{array}$ \\
\hline 165 & & (benzoilazandiil) & & $(\text { benzoilimino })^{\mathrm{h}}$ & 2 \\
\hline 166 & $-\mathrm{NH}_{2}{ }^{+}$ & azanijdiil & & iminio $^{h}$ & 2,14 \\
\hline 167 & $\begin{array}{r}\mathrm{CH}_{3} \\
1 \mathrm{~N} \\
-\mathrm{N}^{+}- \\
\stackrel{1}{\mathrm{CH}_{3}}\end{array}$ & (dimetilazanijdiil) & & ${\text { (dimetiliminio })^{\mathrm{h}}}^{\mathrm{h}}$ & $1,2,14,16$ \\
\hline 168 & $-\mathrm{N}=$ & azanililiden & & nitrilo $^{b}$ & $1,2,10,14$ \\
\hline 169 & $-\mathrm{NH}-\mathrm{NH}-$ & hidrazin-1,2-diil & diazan-1,2-diil & hidrazo & $1,2,13,14,18$ \\
\hline 170 & $-\mathrm{N}=\mathrm{N}-$ & diazendiil & azo & & 2 \\
\hline 171 & $\begin{array}{l}\stackrel{\mathrm{I}}{\mathrm{I}}=\mathrm{N}- \\
-\mathrm{N}\end{array}$ & (1-oksidodiazen-1-ij-1,2-diil) & (ONN-azoksi) & & 1,2 \\
\hline 172 & $-\mathrm{N}=\mathrm{N}-\mathrm{H}-$ & triaz-1-en-1,3-diil & triazen-1,3-diil & triazendiil; azoimino & 2 \\
\hline 173 & $-\stackrel{\mathrm{H}}{\mathrm{N}}-\underset{\mathrm{O}}{\mathrm{C}}-\mathrm{H}-$ & azandiilkarbonilazandiil & & $\begin{array}{c}\text { iminokarbonil= } \\
\text { imino }^{\mathrm{e}, \mathrm{h}} ; \\
\text { ureilen; } \\
\text { karbonilbisazandiilk }^{\mathrm{k}}\end{array}$ & 14 \\
\hline 174 & $\begin{aligned} & \mathrm{OC}_{2} \mathrm{H}_{5} \\
= & \stackrel{P}{\mathrm{P}-} \\
& \mathrm{OC}_{2} \mathrm{H}_{5}\end{aligned}$ & (dietoksi- $\lambda^{5}$-fosfanililiden) & & (dietoksi- $\lambda^{5}$-fosfantriil) & 2 \\
\hline 175 & $\begin{aligned} & \mathrm{OC}_{2} \mathrm{~F}_{5} \\
= & \stackrel{\mathrm{P}-}{\mathrm{I}-} \\
& \mathrm{OC}_{2} \mathrm{~F}_{5}\end{aligned}$ & $\begin{array}{l}\text { [bis(pentafluoretoksi)- } \\
-\lambda^{5} \text {-fosfanililiden] }\end{array}$ & & & 14 \\
\hline 176 & $\begin{aligned} & \mathrm{Cl} \\
= & \stackrel{\mathrm{P}}{\mathrm{P}}- \\
& \mathrm{Cl}\end{aligned}$ & (diklor- $\lambda^{5}$-fosfanililiden) & & & 14 \\
\hline 177 & $\begin{array}{c}\mathrm{OH} \\
-\mathrm{P}- \\
\mathrm{P}- \\
\mathrm{O}\end{array}$ & (hidroksifosforil) & & $\begin{array}{l}\text { (hidroksifosfonoil); } \\
\text { fosfiniko }\end{array}$ & 6 \\
\hline 178 & $\begin{aligned} & \mathrm{CH}_{3} \\
&-\mathrm{P}- \\
& \mathrm{I}\end{aligned}$ & (metilfosfonoil) & & $\begin{array}{l}\text { (metilfosforil); } \\
\text { (metilfosfiniliden) }\end{array}$ & 6 \\
\hline 179 & $-\mathrm{SiH}_{2}-$ & silandiil & & sililen & $1,2,13$ \\
\hline 180 & $\begin{aligned} & \mathrm{CH}_{3} \\
&- \mathrm{Si}- \\
& \mathrm{I} \\
& \mathrm{C}_{6} \mathrm{H}_{5}\end{aligned}$ & [metil(fenil)silandiil] & & (metilfenilsililen) & 2 \\
\hline 181 & $\begin{aligned} \mathrm{CH}_{3} \\
-\mathrm{Si}- \\
\stackrel{\mathrm{I}}{\mathrm{C} \mathrm{H}_{3}}\end{aligned}$ & (dimetilsilandiil) & & (dimetilsililen) & $10,13,14,21$ \\
\hline 182 & $\begin{array}{r}\mathrm{CH}_{3} \\
-\mathrm{Sn}- \\
\stackrel{1}{\mathrm{CH}_{3}}\end{array}$ & (dimetilstanandiil) & & (dimetilstanilen) & $9,14,21$ \\
\hline 183 & $\begin{array}{r}\mathrm{CH}_{3} \\
-\mathrm{Ge}- \\
\mathrm{I} \\
\mathrm{CH}_{3}\end{array}$ & (dimetilgermandiil) & & (dimetilgermilen) & 14 \\
\hline 184 & $\xi-\pi\rangle$ & 1H-pirol-2,5-diil & pirol-2,5-diil & & 14 \\
\hline
\end{tabular}




\begin{tabular}{|c|c|c|c|c|c|}
\hline Br. & $\begin{array}{l}\text { Kemijska } \\
\text { struktura KJ-a }\end{array}$ & Preferentna imena KJ-a* & $\begin{array}{l}\text { Druga prihvatljiva } \\
\text { imena KJ-a* }\end{array}$ & $\begin{array}{l}\text { Neprihvatljiva imena } \\
\text { KJ-a* i objašnjenja }\end{array}$ & $\begin{array}{l}\text { Dokum., } \\
\text { lit. }\end{array}$ \\
\hline 185 & $\xi\left\langle||{ }^{\xi}\right|$ & 1H-pirol-3,4-diil & pirol-3,4-diil & & 1,2 \\
\hline
\end{tabular}

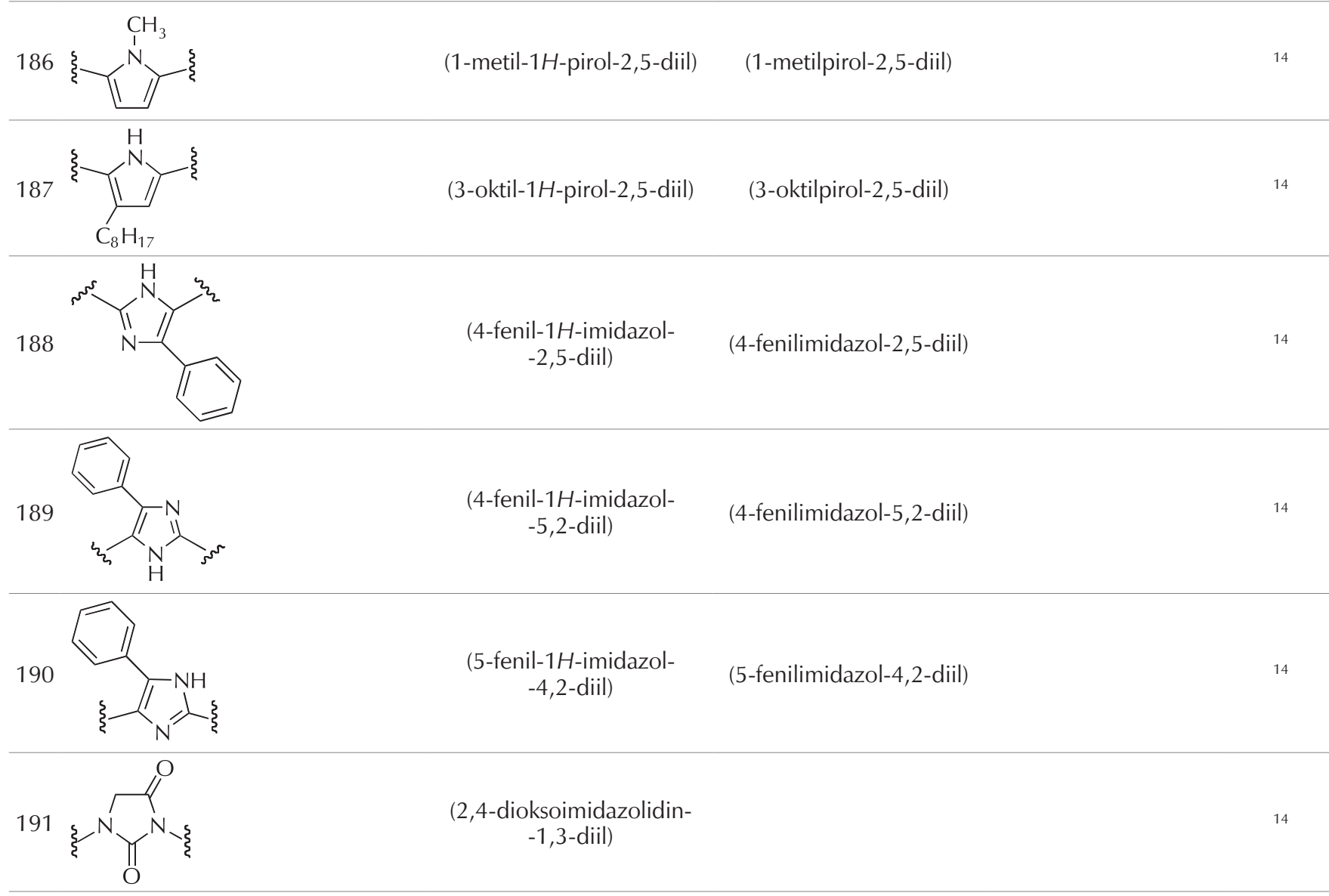

192 (2,5-dioksoimidazolidin-




\begin{tabular}{|c|c|c|c|c|c|}
\hline Br. & $\begin{array}{l}\text { Kemijska } \\
\text { struktura KJ-a }\end{array}$ & Preferentna imena $\mathrm{KJ}-\mathrm{a}^{*}$ & $\begin{array}{l}\text { Druga prihvatljiva } \\
\text { imena KJ-a* }\end{array}$ & $\begin{array}{l}\text { Neprihvatljiva imena } \\
\text { KJ-a* i objašnjenja }\end{array}$ & $\begin{array}{l}\text { Dokum., } \\
\text { lit. }\end{array}$ \\
\hline 198 & & 1,2,3-tiadiazol-5,4-diil & & $\begin{array}{c}\text { preferentna PKJ } \\
\text { homopolimera: } \\
\text { 1,2,3-tiadiazol-4,5-diil }\end{array}$ & 14 \\
\hline 199 & & 1,2,4-tiadiazol-5,3-diil & & $\begin{array}{c}\text { preferentna PKJ } \\
\text { homopolimera: } \\
\text { 1,2,4-tiadizol-3,5-diil }\end{array}$ & 14 \\
\hline 200 & & 1,2,5-tiadiazol-3,4-diil & & & 14 \\
\hline 201 & & 1,3,4-tiadiazol-2,5-diil & & & 14 \\
\hline 202 & & furan-2,5-diil & & & 14 \\
\hline 203 & & (2,5-dioksooksolan-3,4-diil) & $\begin{array}{l}\text {-dioksotetrahidrofu } \\
\text {-3,4-diil) }\end{array}$ & & 14,15 \\
\hline 204 & $\xi-$ & tiofen-2,4-diil & & & 13 \\
\hline 205 & गे & tiofen-2,5-diil & & & 13,14 \\
\hline
\end{tabular}

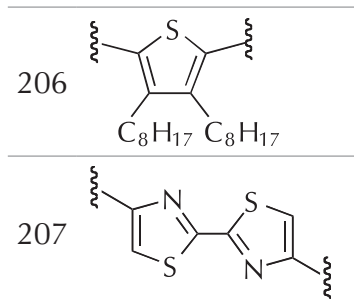

(3,4-dioktiltiofen-2,5-diil)

$208 \xi-N-\xi$

[2,2'-bi(1,3-tiazol)]-4,4'-diil

209

piperidin-1,4-diil

210 约

piperidin-2,4-diil

2,4-piperidindiil

1, 2

piperidin-3,5-diil

${ }^{211}$

$\xi-\mathrm{NH}_{\xi} \xi$

piperidin-4,2-diil

4,2-piperidindiil

1, 2<smiles>CCC1CNCC(C)C1</smiles>

piperidin-3,5-diiliden<smiles>Cc1cccc(I)n1</smiles>

piridin-2,6-diil

$$
214 \text { 倠 }
$$

piridin-2,4-diil

2,4-piridindiil; piridin-2,4-ilen<smiles>Ic1cncc(C[134I])c1</smiles>

piridin-3,5-diil

3,5-piridindiil 


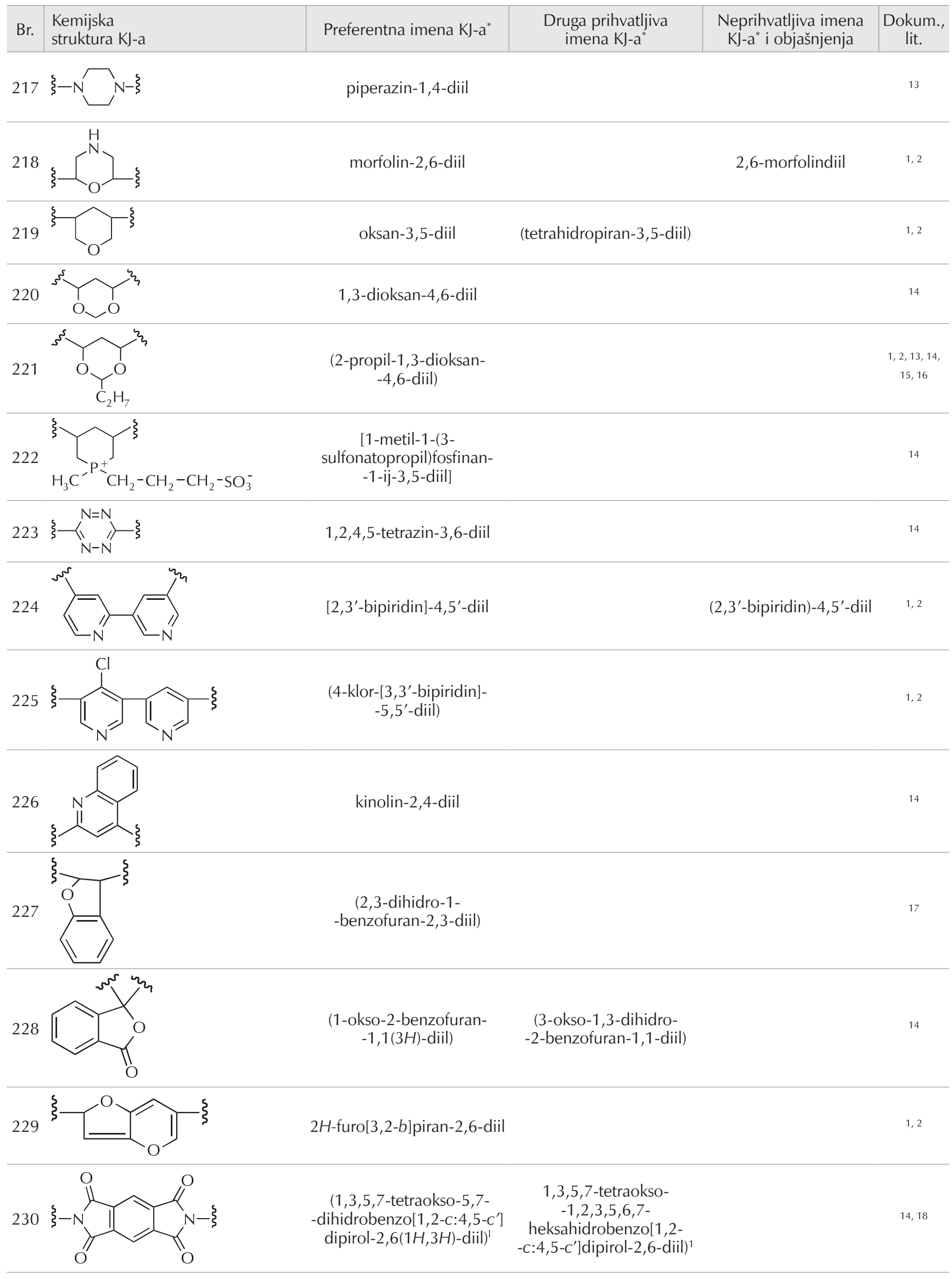


B

Kemijska struktura KJ-a<smiles>Cc1nc2cc3nc(C)[nH]c3cc2[nH]1</smiles><smiles>Cc1ccc2c(c1)Nc1cc(I)ccc1O2</smiles>

233<smiles>Cc1ccc2c(c1)Sc1cc(I)ccc1S2</smiles><smiles>Cc1nc2ccc(-c3ccc4nc(C)oc4c3)cc2o1</smiles>

235<smiles>Cc1nc2ccc(-c3ccc4nc(I)sc4c3)cc2s1</smiles>

236<smiles>Cc1nc2cc(-c3ccc4[nH]c(C)nc4c3)ccc2[nH]1</smiles>

Preferentna imena KJ-a*

(1,5-dihidrobenzo[1,2 $\left.-d: 4,5-d^{\prime}\right]$ diimidazol-2,6-diil)

10H-fenoksazin-2,8-dii

tiantren-2,8-diil

[6,6'-bi(1,3-benzoksazol)]$-2,2^{\prime}$-diil

[6,6'-bi(1,3-benzotiazol)] $-2,2^{\prime}$-diil

$1 H, 1^{\prime} H-\left[5,5^{\prime}-\right.$

-bibenzimidazol]-2,2'-diil

[5,5'-bibenzimidazol]$-2,2^{\prime}$-diil 2,8-fenoksazindiil $\quad 1,16$<smiles>[Z8]Cn1c(=O)c2ccc(-c3ccc4c(c3)C(=O)N(CC)C4=O)cc2c(=O)n1C[Z19]</smiles>

238<smiles>Cc1ccc2ncccc2c1</smiles><smiles>C1=CCC(=CC2=CCCC2)C1</smiles><smiles>C=CN=C</smiles><smiles>CCc1nc2ccccc2nc1-c1ccccc1</smiles>

[3,3'-bikinolin]-6,6'-dii

(3, 3'-difenil[6,6'-bikinoksalin]-2,2'-diil)

spiro[3.5]nona-

-2,5-dien-7,1-diil

spiro[4.5]dekan-2,8-diil

(5-oksaspiro[3.5]nonan-

$$
\text { -2,7-diil) }
$$

$(2,4,8,10$-tetraoksaspiro[5.5] $=$ undekan-3,9-diil)

(2,4,8,10-tetraoksaspiro[5.5] $=$ undekan-3,3,9,9-tetrail)

spiro[3.5]nona-2,5-dien-7,1-ilen non-2,7-ilen) metantriil

243<smiles>CC1OCC2(CO1)COC(C)OC2</smiles>

244<smiles>CC1(C)OCC2(CO1)COC(C)(C)OC2</smiles>

245

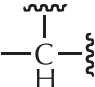

$246 \xi-\stackrel{C}{C}-\xi$

metantetrail 
$\mathrm{Br}$

Kemijska

struktura KJ-a
Preferentna imena KJ-a*

nitrilo
Druga prihvatljiva imena $\mathrm{KJ}-\mathrm{a}^{*}$

azantriil

$247 \stackrel{\text { ? }}{\mathrm{N} N \mathrm{~N}-\xi}$

germantetrail

$248 \stackrel{\xi}{1}-\mathrm{Ge}-\xi$

Neprihvatljiva imena

Dokum., KJ-a* i objašnjenja<smiles>Cc1cc(C)cc(CCC(C)C)c1</smiles>

benzen-1,3,5-triil

1,3,5-benzentriil<smiles>CC1CCCC(C)N1C</smiles>

piperidin-1,2,6-triil<smiles>CCc1cc2nc(C)c(C)nc2cc1C</smiles>

kinoksalin-2,3:6,7-tetrail<smiles>[R5]Cc1nc2cc3c(cc2n1CCC)N=c1c2cc4c(cc2c(=O)n14)C3(C)C</smiles>

(10-oksoimidazo[4,5-f] $=$ izoindolo[2,1-a] benzimidazol$-2,3(10 H): 7,8$-tetrail) (10-okso-3,10-

-dihidroimidazo[4,5- $f]=$

izoindolo[2,1-a]

benzimidazol-2,3:7,8-tetrail)

\footnotetext{
* Objašnjenje simbola jednako (=) upotrijebljenoga u tablici 1 opisano je u zadnjem odlomku odjeljka PIP-2

${ }^{a}$ Metilidin je ime skupine $\mathrm{H}-\mathrm{C} \equiv \mathrm{s}$ trostrukom vezom na ugljiku.

${ }^{\mathrm{b}}$ Ime upućuje na drugačiju strukturu.

${ }^{\mathrm{C} I m e}$ se više ne upotrebljava za PKJ, jer se bočne skupine smatraju supstituentima.

${ }^{\mathrm{d}}$ Viniliden je ime skupine $\mathrm{CH}_{2}=\mathrm{C}=$ (eteniliden) s dvostrukom vezom na ugljiku.

${ }^{\mathrm{e}}$ Iminokarbonil je prijašnje ime konstitucijske jedinice $-\mathrm{NH}-\mathrm{CO}-$, točno ime je azandiilkarbonil.

${ }^{\mathrm{f}}$ Nejasno jer se upotrebljava i za različite strukture.

gPrema IUPAC-ovom imenovanju organske kemije "a" imenovanje je primjenljivo na heterolance s četiri ili više heteroatomskih jedinica (vidi P-51.4.1.1 u lit. ${ }^{6}$ ). PKJ-i poput onih u natuknicama 103-105 upotrijebljeni su u lit. ${ }^{2}$ za prikaz seniornosti jedinica i heteroatoma. Imena temeljena na "a" imenovanju u tom su dokumentu navedena kao dodatna imena. Takve jedinice vrlo se rijetko pojavljuju kao PKJ u stvarnim pravilnim polimerima ili kao konstitucijske jedinice u nepravilnim polimerima. Uporaba "a" imenovanja za acikličke sastojke nije prihvatljiva u imenovanju polimera.

${ }^{\text {h }}$ Uvriježeno ime obiju skupina $>\mathrm{NH}$ (ili $-\mathrm{NH}-$ ) $\mathrm{i}=\mathrm{NH}$ bilo je imino. Kako ta imena mogu izazvati nejasnoće, određeno je, u skladu s lit. ${ }^{6}$, ime azandiil za skupinu $-\mathrm{NH}-$, a ime imino ostaje za skupinu $=\mathrm{NH}$.

i Slova $o, m$ i $p$ upotrebljavana su kao lokanti umjesto ortho, meta i para za označivanje izomera disupstituiranoga benzena na položajima: 1,2-, 1,3- i 1,4-. Ta upotreba nije zadržana u IUPAC-ovom imenovanju (P-14.3.1, lit. $\left.{ }^{6}\right)$.

¡Sve konstitucijske jedinice u glavnome lancu polimera treba imenovati po redu.

kPri imenovanju podjedinica za KJ i PKJ ne treba primjenjivati operacije umnožavanja, jer se sve konstitucijske jedinice glavnoga lanca polimera imenuju po redu.

'Od 1993. prefiksi hidro- se ne svrstavaju abecednim redom kao drugi supstitucijski prefiksi, nego se nakon supstitucijskih prefikasa stavljaju na početak
} imena modificiranoga osnovnog hidrida, vidi R-4.1, napomena 49 u lit. $^{3}$ i P-31.2.1 u lit. ${ }^{6}$ 


\section{Literatura \\ References}

1. Nomenclature of regular single-strand organic polymers. IUPAC Recommendations 1975, Pure Appl. Chem. 48 (3) (1976) 373-386. Hrvatski prijevod: V. Jarm, Z. Smolčić Žerdik, Nomenklatura pravilnih jednolančanih organskih polimera. Preporuke IUPAC 1975., preporuke HDKI i HKD 1988., Kem. Ind. 37 (10) (1988) B50-B60.

2. J. Kahovec, R. B. Fox, K. Hatada, Nomenclature of regular single-strand organic polymers. IUPAC Recommendations 2002, Pure Appl. Chem. 74 (10) (2002) 1921-1956. (Poglavlje 15 u lit. 5). Hrvatski prijevod: V. Jarm, Nomenklatura pravilnih jednonitnih organskih polimera. Preporuke IUPAC 2002., preporuke HDKI i HKD 2005., Kem. Ind. 55 (2) (2006) 81-104.

3. R. Panico, W. H. Powell, J.-C. Richer, A Guide to IUPAC Nomenclature of Organic Compounds, Blackwell Scientific, Oxford 1993. Hrvatski prijevod: I. Bregovec, Š. Horvat, K. Majerski, V. Rapić, Vodič kroz IUPAC-ovu nomenklaturu organskih spojeva. Preporuke IUPAC 1993., preporuke HKD i HKDI 2001., Školska knjiga, Zagreb, 2002.

4. H. A. Favre, K.-H. Hellwich, G. P. Moss, W. H. Powell, J. G. Traynham, Corrections to A Guide to IUPAC Nomenclature of Organic Compounds, Pure Appl. Chem. 71 (7) (1999) 1327-1330.

5. R. C. Jones, J. Kahovec, R. S. E. Stepto, E. S. Wilks, M. Hess, T. Kitayama, W. V. Metanomski, Compendium of Polymer Terminology and Nomenclature, IUPAC Recommendations 2008, $2^{\text {nd }}$ Ed., "Ljubičasta knjiga" (the "Purple Book"), RSC Publishing, Cambridge, UK, 2009.

6. A. H. Favre, W. H. Powell, Nomenclature of Organic Chemistry. IUPAC Recommendations and Preferred Names 2013, XLIII, RSC Publishing, Cambridge, UK, 2014, ISBN: 9780-85404-182-4; popis pogrešaka može se naći na mrežnoj stranici http://www.chem.qmul.ac.uk/iupac/bibliog/ BBerrors.html.

7. N. G. Connelly, T. Damhus, R. M. Hartshorn, A. T. Hutton, Nomenclature of Inorganic Chemistry. IUPAC Recommendations 2005. RSC Publishing, Cambridge, UK, 2005, ISBN: 0-85404-438-8.

8. R. G. Jones, T. Kitayama, K.-H. Hellwich, M. Hess, A. D. Jenkins, J. Kahovec, P. Kratochvíl, I. Mita, W. Mormann, Ch. K. Ober, S. Penczek, R. S. T. Stepto, K. Thurlow, J. Vohlídal, E. S. Wilks, Source-based nomenclature for single-strand homopolymers and copolymers. IUPAC Recommendations 2016, Pure Appl. Chem. 88 (10-11) (2016) 1073-1100. Hrvatski prijevod: V. Jarm, Imenovanje jednonitnih homopolimera i kopolimera na osnovi podrijetla (I. dio). Preporuke IUPAC 2016., preporuke HDKI i HKD 2018., Kem Ind. 67 (3-4) (2018) 135-144, doi: https://doi.org/10.15255/KUI .2017.012a. Imenovanje jednonitnih homopolimera i kopolimera na osnovi podrijetla (II. dio). Preporuke IUPAC 2016. preporuke HDKI i HKD 2018., Kem Ind. 67 (5-6) (2018) 219-234, doi: https://doi.org/10.15255/KUI.2017.012b.

9. R. B. Fox, N. M. Bikales, K. Hatada, J. Kahovec, Structure-based nomenclature for irregular single-strand organic polymers. IUPAC Recommendations 1994, Pure Appl. Chem. 66 (4) (1994) 873-889. (Poglavlje 17 u lit. 5). Hrvatski prijevod: V. Jarm, Nomenklatura na osnovi strukture za jednonitne organske polimere. Preporuke IUPAC 1994., preporuke HDKI i HKD 1998., Kem. Ind. 47 (12) (1998) B43-B49.

10. W. Mormann, K.-H. Hellwich, Structure-based nomenclature for cyclic organic macromolecules. IUPAC Recommendati- ons 2008, Pure Appl. Chem. 80 (2) (2008) 201-232. Hrvatski prijevod: V. Jarm, Nomenklatura za cikličke organske makromolekule na osnovi strukture. Preporuke IUPAC 2008., preporuke HDKI i HKD 2013., Kem. Ind. 62 (9-10) (2013) 327-344.

11. R. C. Hiorns, R. J. Boucher, R. Duhlev, K.-H. Hellwich, P. Hodge, A. D. Jenkins, R.G. Jones, J. Kahovec, G. Moad, C.K. Ober, D.W. Smith, R.F.T. Stepto, J.-P. Varion, J. Vohlídal, A brief guide to polymer nomenclature. IUPAC technical report, Pure Appl. Chem. 84 (10) (2012) 2167-2169. Hrvatski prijevod: V. Jarm, Kratki vodič kroz nomenklaturu (imenovanje) polimera. IUPAC tehničko izvješće, preporuke HDKI i HKD 2015., Kem Ind. 65 (3-4) (2016) 153-160, doi: https://doi. org/10.15255/KUI.2014.022.

12. G. J. Leigh, Principles of Chemical Nomenclature. A guide to IUPAC Recommendations, RSC Publishing, Cambridge, UK, 2011, XII, 257 pp.

13. IUPAC. Guide for the Authors of Papers and Reports in Polymer Science and Technology (pdf June 2001). Vodič je dostupan na mrežnoj stranici http://old.iupac.org/reports/IV/ guide.html, ali je zastario. Dokument je u procesu obnavljanja (http://www.iupac.org/project/2008-020-1-400).

14. M. Barón, K.-H. Hellwich, M. Hess, K. Horie, A. D. Jenkins, R. G. Jones, J. Kahovec, P. Kratochvíl, W.V. Metanomski, W. Mormann, R.F.T. Stepto, E.S. Wilks, Glossary of class names of polymers based on chemical structure and molecular architecture. IUPAC Recommendations 2009, Pure Appl. Chem. 81 (6) (2009) 1131-1186. Hrvatski prijevod: V. Jarm, Glosar razrednih imena polimera na osnovi kemijske strukture i molekulne arhitekture. Preporuke IUPAC 2009., preporuke HDKI i HKD 2012., Kem. Ind. 61 (3) (2012) 145-176.

15. E.S. Wilks, J.I. Schultz, Introduction to polymer nomenclature. (Poglavlje 14 u lit. 5). Hrvatski prijevod: V. Jarm, Uvod u nomenklaturu (imenovanje) polimera, Kem. Ind. 60 (4) (2011) 201-215.

16. N. A. Platé, I. M. Papisov, A classification of linear single-strand polymers. IUPAC Recommendations 1988, Pure Appl. Chem. 61 (2) (1989) 243-254. Hrvatski prijevod: V. Jarm, Podjela linearnih jednolančanih polimera. Preporuke IUPAC 1988., preporuke HDKI i HKD 1992., Kem. Ind. 41 (2) (1993) B31-B37.

17. K. Hatada, J. Kahovec, M. Barón, K. Horie, P. Kubisa, G. P. Moss, R. F. T. Stepto, E. S. Wilks, Definitions relating to stereochemically asymmetric polymerization. IUPAC Recommendations 2001, Pure Appl. Chem. 74 (6) (2002) 915-922. (Poglavlje 5 u lit. 5). Hrvatski prijevod: V. Jarm, Definicije koje se odnose na stereokemijski asimetrične polimerizacije. Preporuke IUPAC 2001., preporuke HDKI i HKD 2005., Kem. Ind. 55 (1) (2006) 23-28.

18. E. Maréchal, E. S. Wilks, Generic source-based nomenclature for polymers. IUPAC Recommendations 2001, Pure Appl. Chem.73 (9) (2001) 1511-1519. (Poglavlje 21 u lit. 5). Hrvatski prijevod: V. Jarm, Generička nomenklatura polimera na osnovi podrijetla. Preporuke IUPAC 2001., preporuke HDKI i HKD 2005., Kem Ind. 55 (2) (2006) 73-80.

19. A. D. Jenkins, Stereochemical definitions and notations relating to polymers. IUPAC Recommendations 1980, Pure Appl. Chem. 53 (3) (1981) 733-752. (Poglavlje 2 u lit. 5). Hrvatski prijevod: V. Jarm, Z. Smolčić Žerdik, Stereokemijske definicije i oznake koje se odnose na polimere. Preporuke IUPAC 1980., preporuke HDKI i HKD 1988., Kem. Ind. 37 (10) (1988) B38-B50.

20. R. E. Bariess, J Kahovec, P. Kratochvíl, Graphic representations (chemical formulae) of macromolecules. IUPAC Recommen- 
dations 1994, Pure Appl. Chem. 66 (12) (1994) 2469-2482. (Poglavlje 18 u lit. 5). Hrvatski prijevod: V. Jarm, Grafičko prikazivanje (kemijske formule) makromolekula. Preporuke IUPAC 1994., preporuke HDKI i HKD 1998., Kem. Ind. 47 (12) (1998) B34-B42.

21. L. G. Donaruma, B. P. Block, K. L. Loening, N. A. Platé, T. Tsuruta, K. Ch. Buschbeck, W. H. Powell, J. Reedijk, Nomenclature for regular single-strand and quasi single-strand inorganic and coordination polymers. IUPAC Recommendations
1984, Pure Appl. Chem. 57 (1) (1985) 149-168. (Dokument je na reviziji). Hrvatski prijevod: V. Jarm, Nomenklatura pravilnih jednolančanih i kvazijednolančanih anorganskih i koordinacijskih polimera. Preporuke IUPAC 1984., preporuke HDKI i HKD 1992., Kem. Ind. 42 (2) (1993) B21-B31.

22. J. Brecher, Graphical representation standards for chemical structure diagrams. IUPAC Recommendations 2008, Pure Appl. Chem. 80 (2) (2008) 277-410.

\title{
SUMMARY
}

\author{
Preferred Names of Constitutional Units for Use in Structure-based Names of \\ Polymers (Part I) (IUPAC Recommendations 2016) \\ Translated by Vida Jarm
}

\begin{abstract}
A list of constitutional units (CU) used for naming polymers according to IUPAC nomenclature rules is provided. This list contains CUs of commercial and well-known polymers, as well as CUs which have been used in polymer-nomenclature-related IUPAC documents. A preferred name is provided for each constitutional unit. Other acceptable names and names which must not be used because they are outdated or incorrect, although they may have been correct in the past or in a different context, are also listed. A second table contains names of common polymers: structure-based, source-based, and retained traditional polymer names, as well as names that are not acceptable, again because they are outdated or incorrect. These tables supersede similar tables and names in previous documents. The rules given in those documents are still valid, but names of constitutional units should be checked for agreement with the present document. The preferred names of constitutional units should be used in structure-based names of regular and irregular polymers.
\end{abstract}

\section{Keywords}

IUPAC nomenclature, names of common polymers, names of constitutional units, polymer nomenclature

\author{
Rudolfa Bićanića \\ 10000 Zagreb \\ Croatia
}

Nomenclature note Received November 14, 2017 Accepted September 4, 2018 